\title{
THE CENTRAL NERVOUS SYSTEM IN A CASE OF CYCLOPIA IN HOMO
}

\section{DAVIDSON BLACK}

From the Anatomical Laboratories of the University of Chicago and Western Reserve University

FIFTY-ONE FIGURES

CONTENTS

Introduction.$\ldots \ldots \ldots \ldots \ldots \ldots \ldots \ldots \ldots \ldots \ldots \ldots \ldots \ldots \ldots \ldots \ldots \ldots$

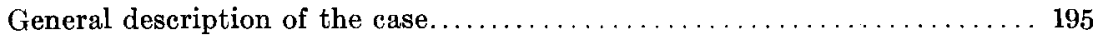

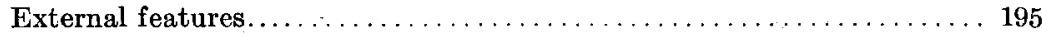

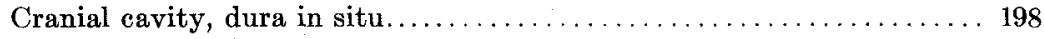

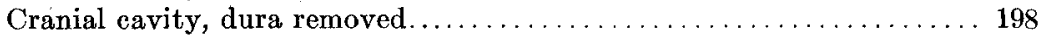

Vascular anomalies.............................. 201

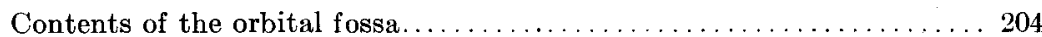

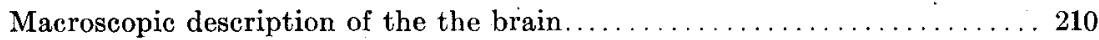

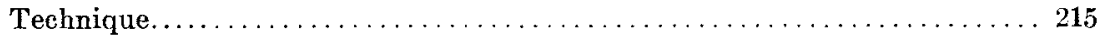

Microscopic description of the brain. . $\ldots \ldots \ldots \ldots \ldots \ldots \ldots \ldots \ldots \ldots \ldots$

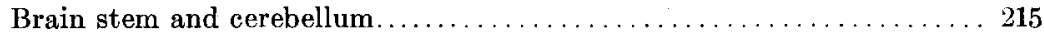

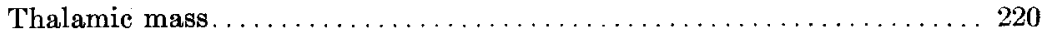

Cerebral vesicle . . . . . . . . . . . . . . . . . . . . . . . . . 222

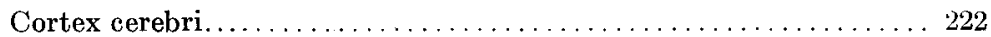

Cerebral limbi................................. 231

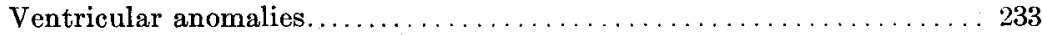

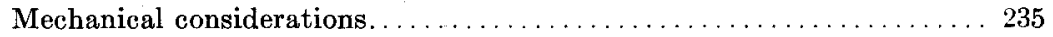

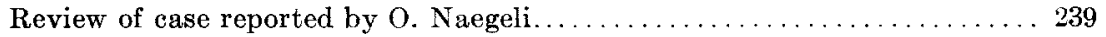

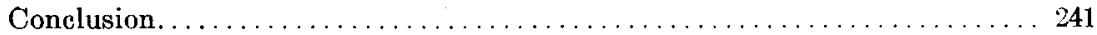

Literature cited $\ldots \ldots \ldots \ldots \ldots \ldots \ldots \ldots \ldots \ldots \ldots \ldots \ldots \ldots \ldots \ldots \ldots$

\section{INTRODUCTION}

Although cyclopia in man is a somewhat rare condition, yet among the cases reported few deal with other than the external features of the malformation. Up to the present, the only investigation into the finer structure of the central nervous system in a case of cyclopia in homo has been made by $\mathrm{O}$. Naegeli in 
v. Monakow's laboratory (17). In the case reported by him, however, the condition of cyclopia was much complicated by the presence of a very extensive malformation in connection with the brain stem and cord, which without doubt was quite independent of the cyclopian condition.

With the exception of a moderate degree of hydrocephalus, the present case presents no malformations other than those which may safely be considered as due to the cyclopic condition. Such being the case, this material is well adapted to determine among other things, whether the cyclopian brain can in any way be regarded as an arrest of development at an early phylogenetic stage, as Naegeli suggests. The research was begun in the hope of clearing up this point, and as will be shown, all the evidence in this case is against the assumption of such a reversion.

The central nervous system is of paramount interest in this case, and the necessarily incomplete general description is only warranted in so far as it records certain data which may be of use in any future complete investigations. In the course of the work, the condition of development in the pallium has proved to be of the greatest interest, as it tends to throw additional light on the subject of the evolution of the normal cortex. This phase of the research has not been as fully dealt with here as is desired, and will be the subject of a future communication.

The cyclopian foetus, upon which the following observations have been made, was obtained in Chicago through the courtesy of Dr. Warren H. Hunter, Cook County Coroner's Physician, and Prof. E. R. Le Count of Rush Medical College, Chicago. The clinical details of the case have already been reported by Dr. Harry Jackson (11).

I am indebted to Prof. C. J. Herrick for the opportunity of taking up this work and for much helpful criticism throughout the investigation. The work was begun in the Anatomical Department of the University of Chicago in the spring quarter of 1910. The major portion of the technique in connection with the microscopic study of the central nervous system and also the examination of this material has been done in the Anatomical Department of Western Reserve University. 
The specimen was preserved immediately after death, under Dr. Le Count's direction, by an injection through the carotid artery of 10 per cent formalin (4 per cent formaldehyde) after which the whole body was immersed in a solution of the same. On account of this careful fixation, the histological preservation was excellent.

A research had been begun upon this specimen before it came into my possession, and on this account $I$ have been unable to determine the exact attachments of the cerebral roof over the thalamic mass. I am indebted to Miss Katherine Hill, medical artist at the Hull Laboratory of Anatomy, for the four drawings of the entire brain made shortly after its removal from the skull cavity and before the relations referred to above had been disturbed.

\section{GENERAL DESCRIPTION OF THE CASE}

\section{External features}

The body is that of a well developed male infant weighing seven and one-half pounds. The head is enlarged and shows a condition of moderate hydrocephalus so that the cranium cerebrale is considerably more developed than the cranium viscerale. The skull is dolichocephalic, though not markedly so, as is usually the case in hydrocephalus (18) It measures $95 \mathrm{~mm}$. in greatest transverse diameter, and $130 \mathrm{~mm}$. in greatest longitudinal diameter, the cephalic index being 73. The sagittal suture is widely open, the parietal bones being separated from one another by a considerable space $(2$ to $3 \mathrm{~cm}$.) throughout. The metopic suture is also widely open, its lateral margins being separated in the upper part by a distance of $10 \mathrm{~mm}$.

At the base of the regio frontalis, which is high and prominent, in the mid-line is a finger-like process of about $2 \mathrm{~cm}$. in length. The walls are firm and it presents at its distal extremity a single orifice which leads into a blind passage extending inward as far as the attached end of the organ. This appendage, which probably represents an abortive naso-frontal process, overhangs the single median eye (fig. 1). 
The eyeball protrudes from the orbital fossa and is somewhat larger in its transverse than in its vertical diameter. The cornea is 'dumb-bell' in shape-the long axis of the dumb-bell, which is slightly asymmetrical, being transverse. The condition of the pupil could not be accurately determined on account of the opacity of the cornea. The exposed superior surface of the bulbus is of dark brownish black color, due to the thinness of the

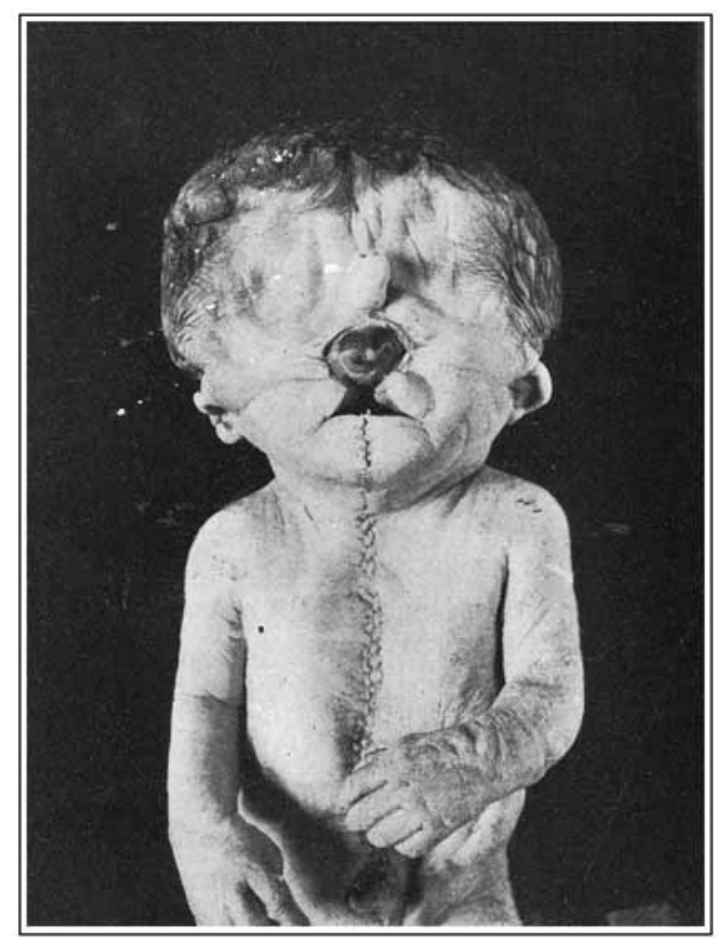

Fig. 1 Photograph of the specimen

sclera overlying the uveal pigment. The superior palpebrae are represented by two thickened ridges sparsely beset with cilia and separated from one another by a notch immediately below the base of the overhanging proboscis. In either side a notch representing the outer canthus limits these ridges laterally. The inferior palpebrae are represented on either side by short blunt tubercles bearing a few cilia and situated immediately below 
and to the inner side of the external canthi. The remainder of the inferior margin of the orbit for the short distance medial to the tubercles representing the lower lids is formed on either side by the palatine processes of the maxillary elements. Owing to a condition of hare lip and partial cleft palate, a boundary in the mid-line ventrally is lacking between the mouth cavity and the conjunctival sac above.

It thus happens that the mucous membrane lining the roof of the mouth becomes continuous with that lining the conjunctival sac, around the margins of the cleft palate (fig. 2). The

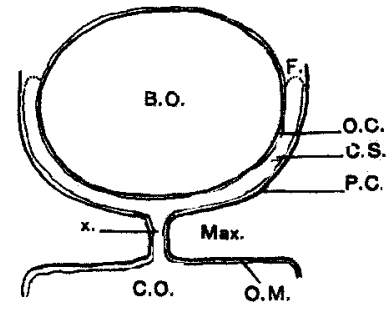

2

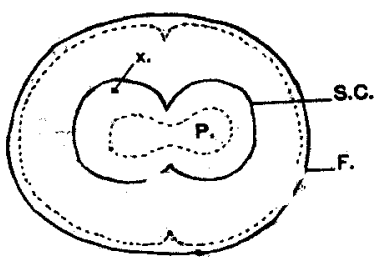

3

Fig. 2 Schematic coronal section through face region, showing relations of oral cavity and conjunctival sac. B.O.. bulbus oculi; C.O., oral cavity; O.C., ocular conjunctiva, continuous with the parietal layer $(P . C$.$) , at the fornix con-$ junctivae $(F)$, which is indicated in dotted lines as being on a deeper plane; $O . M$., oral mucosa whioh becomes continuous with the parietal layer of the conjunctiva (P.C.), through the cleft $(X)$ between the maxillary elements $(M a x)$.

Fig. 3 Diagram of anterior surface of bulbus. $F$., fornix conjuntivae indicated in dotted lines; $P$., pupil; S.C., sclero-corneal junction; $x$., small pigmented area. at margin of cornea

condition of cleft palate ceases about $3 \mathrm{~cm}$. from the red margin of the upper lip. In the median line at the point of closure of the palatine cleft the parietal layer of the conjunctiva becomes reflected on to the eyeball. On both sides lateral to this point of attachment, the conjunctival sac extends for some distance backward before the inferior fornix is reached. A similar condition obtains above, the two lateral pouches being separated from one another in the mid line dorsally at the notch situated at the base of the proboscis. These relations will be made clear by reference to the diagram (fig. 3), where the line of reflection of the bulbar conjunctiva is indicated in dotted lines. 
There is thus every indication of bilateral symmetry in the cornea, the conjunctival sac, the palpebrae, and, as will be subsequently seen, in the contents of the orbital fossa.

The uvula and soft palate are present but the posterior nares are represented only by a slight recess above these structures.

\section{Cranial cavity, dura in situ}

As it was desired to preserve the external form of the specimen for museum purposes, many of the following descriptions are necessarily incomplete.

The cranial cavity presents a somewhat elongated appearance, as is indicated in figure 4, and is divided into anterior, middle and posterior fossae.

Posterior fossa. The posterior fossa and its boundaries are approximately normal in appearance. The dural foramina for the exit of the nerves normally leaving the cranial cavity in this region may be made out with the exception of the foramen for the trochlear nerve. The vertebral arteries and the accessory nerves may be made out in the foramen magnum. The internal occipital protuberance is well marked. The attachment and extent of the tentorium are normal.

Middle fossa. The middle fossa is subdivided into two lateral portions by a much elongated, sharp, median ridge. Slightly more than $1 \mathrm{~cm}$. from the anterior end of this ridge, a single large artery opens on its dorsal surface. At its anterior extremity the median ridge becomes continuous with the median process of the posterior boundary of the anterior fossa.

Anterior fossa. The anterior fossa, which is quite extensive, is bounded on either side posteriorly by curved ridges whose concavity is directed backward.

\section{Cranial cavity, dura removed}

Anterior fossa. No ethmoid element can be made out. A wide metopic suture is present (fig. 5). In the mid-line, slightly in front of the junction of the posterior boundary of the anterior fossa with the median ridge of the middle fossa, there is seen a slight prolongation of the dura into a small pit in the bone. 
This subsequently was found to mark the point of attachment of the fibrous remnants of the optic nerves.

Middle fossa. The two carotid arteries enter the skull on either side of the median ridge postero-laterally. The left carotid is a mere fibrous thread, while the right carotid is somewhat larger than normal. The left carotid canal is proportionately reduced. These vessels approach one another, become united on the crest of the median ridge and pass forward as a single vessel. At the
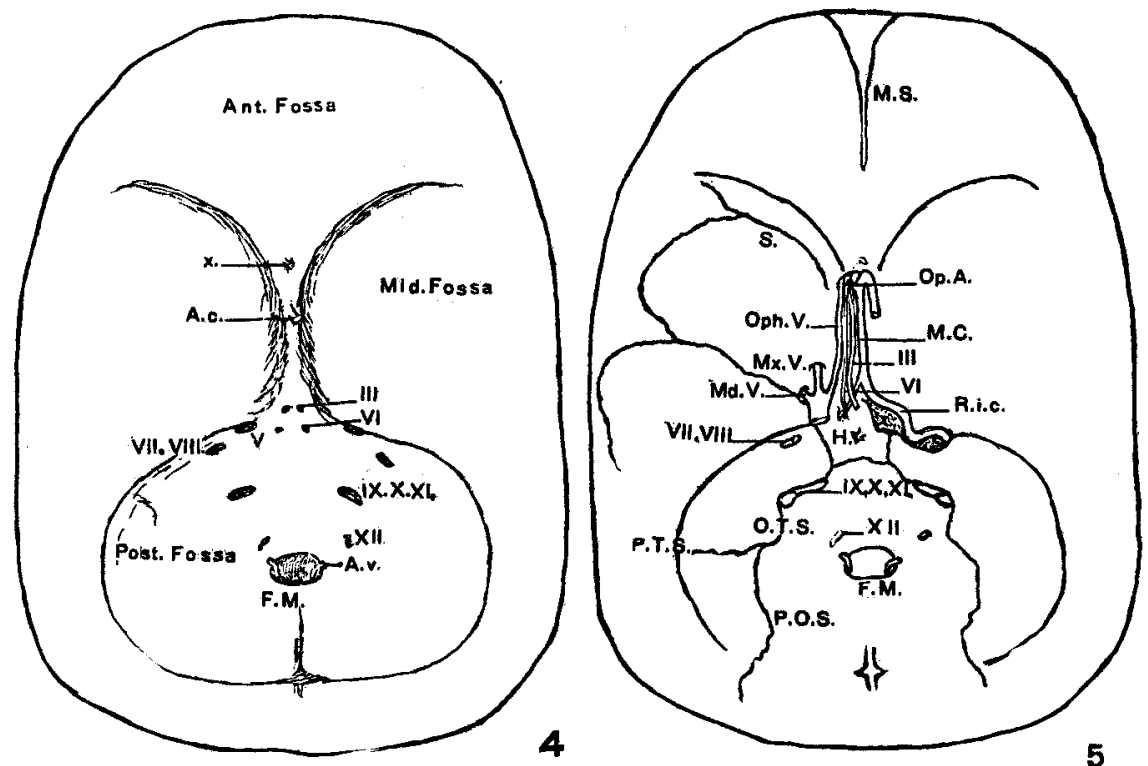

Fig. 4 Diagram of floor of skull cavity, dura in situ. A.c., carotid artery A.v., vertebral artery; $F . M$., foramen magnum; $x$., a slight depression in dura which marks the site of attachment below of the fibrous remnant of the optic nerve. The cranial nerves in their dural foramina are numbered in Roman numerals.

Fig. 5 Diagram of floor of skull cavity, dura removed. F.M., foramen magnum; $H$., pit in basi-sphenoid into which were prolonged fine processes from dura; M.C., median carotid artery; M.S., metopic suture; O.p.A., ophthalmic artery; O.T.S., occipito-temporal suture; P.O.S., parieto-occipital suture; P.T.S., parieto-temporal suture; R.i.c., right internal carotid artery; $S$., suture between great wing of sphenoid and frontal element; $X$., marks the cut surface of bone removed to expose the course of right internal carotid artery; cranial nerves indicated in Roman numerals. The remnant of the left internal carotid artery is indicated beneath the cut ends of the third and sixth nerves. 
anterior extremity of the ridge a small vessel is given off and passes downwards through a median foramen to the orbit. This vessel is an azygos ophthamic artery Immediately after the ophthalmic branch is given off, the main vessel turns backward upon itself and courses a short distance in this direction before passing upward through the dura as the single median artery already noted. There is no appearance whatever of anterior or posterior clinoid processes.

On either side of the median ridge the third and sixth nerves pass forward beneath the dura to the median foramen mentioned above to gain the orbit. Slightly more laterad the ophthalmic division of the fifth nerve passes forward to the same destination. Accompanying the latter is a small nerve which may (?) represent the trochlear though subsequent dissection failed to identify it definitely.

The spheno-temporal suture may be clearly made out, extending outward from the region of the carotid canal. Anteriorly another suture may be made out passing parallel to the posterior boundary of the anterior fossa, and marking the line of union between the frontal element and the great wing of the sphenoid.

Below the posterior end of the median crest, between the entering carotid arteries and behind the point of their junction, there is found a small pit in the basi-sphenoid into which are prolonged a few fine processes from the dura. This depression was not apparent before removal of the dura. Further examination showed that the fornix pharyngis was situated immediately below this pocket. In fact it marks the site where normally the pituitary body should be lodged. Although no pituitary tissue could be identified, I am inclined to view this pit as a remnant of Rathke's pouch.

Posterior fossa. In the posterior fossa the occipito-temporal, the parieto-occipital and the parieto-temporal sutures can readily be made out. The foramina for the exit of the nerves in this region presented no peculiarities. 


\section{Vascular anomalies}

As has hoen already noted, the left internal carotid artery within the skull was reduced to a mere thread-like vessel. Examination also showed that the left carotid canal was proportionately reduced. The right internal carotid is somewhat larger than normal, as might be expected. In examining the origin of these vessels in the neck region it was found that the relations on the right side were normal. On the left side the internal carotid was so much reduced as to be distinguished only with difficulty. It arises from the posterior aspect of the common carotid at about the level of origin of the lingual artery. The left facial artery is somewhat larger than the right (diagram, fig. 6).

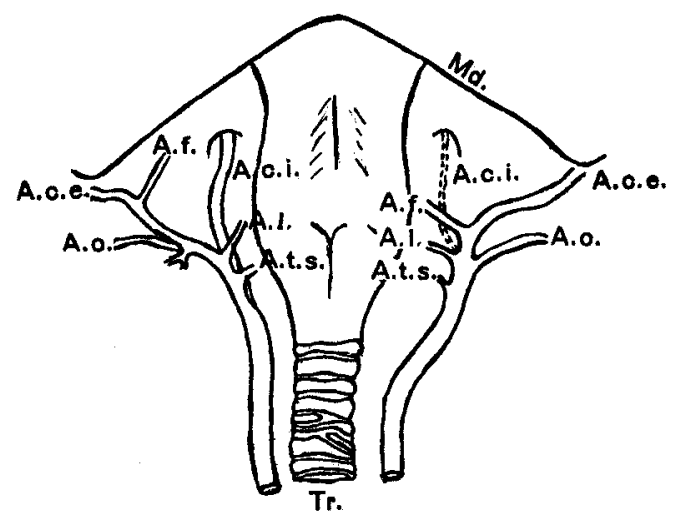

Fig. 6 Diagram of arrangement of arteries in neck region. A.c.e., external carotid artery; $A . c . i$., internal carotid artery; $A . f$. , facial artery; $A . l$. ., lingual artery; $A$. .o., occipital artery; A.t.s., superior thyroid artery; $M d$. ., lower jaw; $T r$. , trachea.

The course of the internal carotid arteries within the skull to the point where a single median vessel pierces the dura, has already been described.

Encephalic arteries. The vessels of this region are represented in figure 7 as pinned out and seen from above. Postreiorly the two vertebral arteries unite in a normal fashion to form the main basilar trunk. The origin of the anterior spinal artery is normal. The posterior inferior cerebellar arteries are small and arise from the basilar. A similar anomaly has been reported by 
Blackburn (1) in a few of his cases. The basilar artery is long and gives off numerous irregular branches. Six pairs of these branches arise in the pontine region. The superior and anterior inferior cerebellar arteries arise from a common branch of the basilar. Of the two, the superior cerebellar is much the smaller.

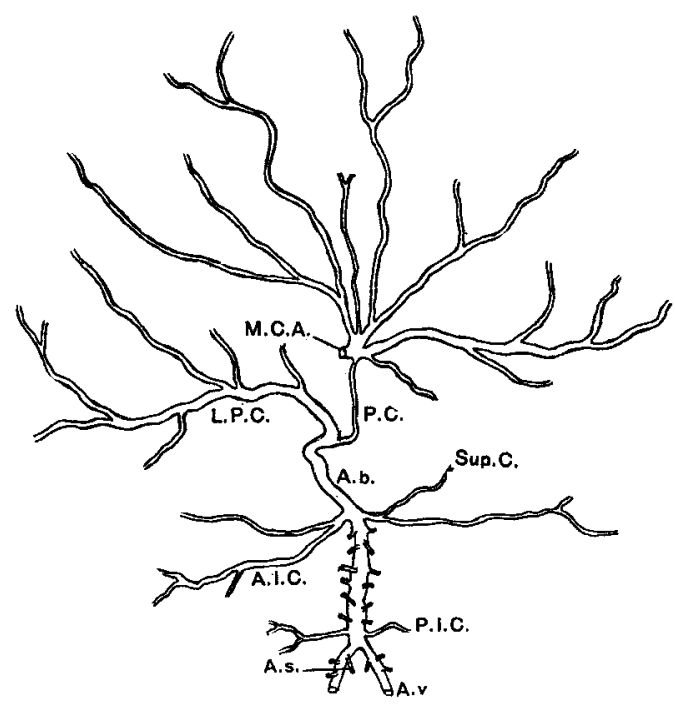

Fig. 7 Diagram of encephalic arteries pinned out and seen from above. A.b., basilar artery; A.I.C., anterior inferior cerebellar artery; $A . s .$, spinal artery; $A . v$., vertebral artery; L.P.C., left posterior cerebral artery; M.C.A., median carotid artery; P.C., posterior communicating artery; P.I.C., posterior inferior cerebellar artery; Sup.C., superior cerebellar artery. $\times \frac{1}{2}$.

Blackburn (q.v.) has noted that when the anterior inferior cerebellar artery is ill developed, the superior cerebellar artery occasionally sends branches to reinforce it. He also noted that when the posterior inferior cerebellar arteries are absent or small, and arising from the basilar, the anterior inferior cerebellar arteries send down compensating branches. In this case, both superior and posterior inferior cerebellar arteries are small and the anterior inferior cerebellar arteries are proportionately enlarged and send branches in both directions. 
Anteriorly the basilar artery becomes continuous with a large left posterior cerebral vessel. No right posterior cerebral artery is present. A small median branch passes forward at the point of origin of the left posterior cerebral artery. This vessel is to be considered as a single posterior communicating artery. It is represented in figure 50 as being much larger than is actually the case.

From the median carotid trunk the cerebral vessels radiate out in such a manner that they become distributed to the right side and anterior portion of the left side of the cerebral vesicle. The posterior portion of the cerebral vesicle on the left side is supplied wholly by the posterior cerebral branch of the basilar artery.

From the vertebral arteries posteriorly to the point of origin of the common trunk of the superior and anterior inferior cerebellar arteries, the encephalic vessels have shown but little variation from the normal condition and may be identified with a reasonable degree of certainty.

Beyond this point there has been a very marked disturbance in the origin and relations of the various vessels supplying the cerebral vesicle.

Mall (14) has shown that under normal circumstances the arrangement of the encephalic vessels arising as branches from the future circle of Willis varies remarkably at different stages in the growth of the embryo.

Anomalies of the encephalic vessels are very commonly met with among the insane (1), more so than among normal individuals. The above fact implies that the growth and arrangement of these vessels is influenced in no small degree by the growth of the cerebral tissue. Very slight anatomical variations in the latter increase the tendency toward vascular anomalies.

When, as in the case in point, there has been a profound disturbance in the development of the primary forebrain vesicle a correspondingly wide deviation from the normal arterial arrangement may be looked for. The anomalies will be partly due to the mechanical difficulties encountered in growth, but mostly to the absence of certain parts of the cerebral tissue itself. 
Thus the conditions of these vessels may be looked upon as being to some extent an indication of the degree of perfection of cerebral growth. The two disturbances cannot be considered as being mutually dependent upon one another, for the cerebral condition in cases such as this is certainly the prime factor.

There is a large blood supply from the median carotid to the right half of the cerebral vesicle, while there is no component to this side from the basilar artery. On the other hand, the left side of the cerebral vesicle receives a large component from the basilar artery which effectually compensates for the small supply derived from the branches of the median carotid trunk on this side. So, although the vessels are asymmetrically arranged, it is to be noted that the blood supply is approximately equal on both sides.

The sharp bend which is seen anteriorly in the median carotid before it pierces the dura is similar to the bending of the normal bilaterally symmetrical vessels before their division into anterior and middle cerebral arteries. It is to be noted in this connection that the single ophthalmic artery arises at this 'genu' as is also the case with the normal ophthalmic arteries.

\section{Contents of the orbital fossa}

The following incomplete dissections were made by removing the roof of the orbital fossa. Only those structures which could be dissected without disturbing the external relations of the bulbus are described. The diagrams represent the structures in this region as seen from above. All the structures examined were essentially symmetrical.

First stratum (fig. 8). On removing the bony roof of the orbital fossa and dissecting away the peribulbar fat and connective tissue, the muscles of this region were found to radiate outwards to their insertions from a central fibrous mass in which are imbedded the remnants of the unpaired optic nerve.

In the region of the central tendon the third nerve divides into a number of small branches and freely communicates with its fellow of the opposite side. 
The sixth nerve comes to lie ventral to the oculomotor and in the region of the central tendon turns laterad and passes to the inferior surface of a muscular band which, from its nerve supply and relations to the bulbus; represents the rectus lateralis muscle.

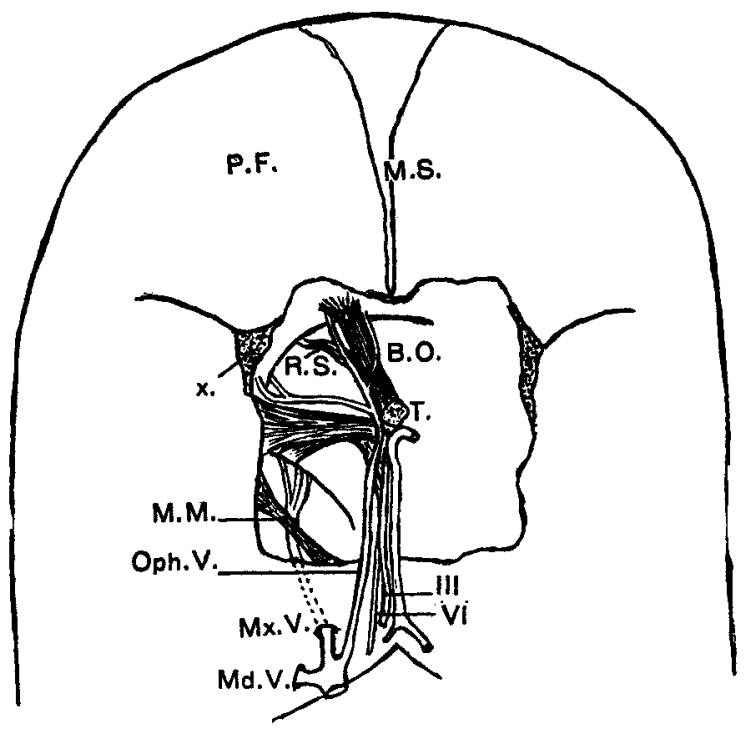

Fig. 8 Diagram of structures exposed on removing the bony roof of orbit. The metopic suture (M.S.) and an outline of the skull fossa are indicated, though not in proportion to the dissection of the orbit. B.O., bulbus oculi; Md.V., mandibular division of the fifth nerve; $M . M$., Müller's muscle overlying the maxillary division of the fifth nerve $(M x . V.) ; O p h . V$., ophthalmic division of the fifth nerve; $P . F$., squama frontalis; $R . S$.; rectus superior muscle; $T$., central tendinous mass; $x$., represents cut surface of bony ridge separating anterior and middle skull fossae; $I I I$, oculomotor nerve: $V I$., abducent nerve.

Lateral to the nerves mentioned, the ophthalmic division of the fifth nerve passes into the orbital fossa. Upon its dorso-medial surface there lies a small nerve which has already been alluded to as the possible representative of the trochlear. The relations of this nerve could not be accurately followed after reaching the region of the central tendon. Here it becomes lost in the median mass of fibrous tissue. 
The ophthalmic division of the fifth nerve is the most dorsally placed nerve trunk in the orbital fossa and at the level of the central tendon it divides into two branches of about equal size. The most mesial branch divides into two parts upon the dorsal surface of a flat muscular band whose origin is from the common central tendon and whose insertion is into the deep fascia of the skin lateral to the notch representing the inner canthus. The branches of the nerve become related to the mesial and lateral borders of this muscle.

The more lateral branch courses laterad almost at right angles to the parent trunk upon the anterior border of a second flat muscular band arising from the central tendon and being inserted into the fascia in the region of the external canthus. All the branches of the ophthalmic division of the fifth nerve enter the subcutaneous tissue at the bony margin of the orbit. Although considerable disturbance occurred in this case in the areas usually supplied by the supratrochlear, frontal, and supraorbital nerves, it is possible that the branches of the fifth nerve here described may correspond to these.

The flattened bands of muscular tissue described in connection with the branches of the fifth nerve are present in essentially similar relations on both sides and probably represent an anomalous arrangement of the levator palpebrae superioris muscle.

Both foramen ovale and foramen rotundum, transmitting respectively the mandibular and maxillary divisions of the fifth nerve, are illustrated in figure 8 , and the course of the maxillary division is indicated in dotted lines till it reaches the space opened for the dissection of the eye. The posterior boundary of the orbital fossa is here seen to be formed by two rounded bony eminences having their convex anterior borders inclined to one another in such a fashion as to form a V-shaped notch in the midline. Examination shows that these apparently represent the bony roofs of the tooth crypts. It is to be noted that the posterior boundary of the orbital fossa is a considerable distance behind the region of the central tendon.

The maxillary division of the fifth nerve passes over the roof of the crypt and is lost sight of at about the middle of the an- 
terior convex margin where it dips down beneath the bulbus oculi. An anomalous band of muscular tissue passes obliquely across the upper aspect of the maxillary element and over the 2nd division of the fifth nerve. From its relation to the nerve this muscle may (?) represent the rudimentary bundle described as Muller's muscle in the normal orbital fossa.

Second stratum (fig. 9). The third and sixth nerves, and the ophthalmic division of the fifth nerve on each side, together with

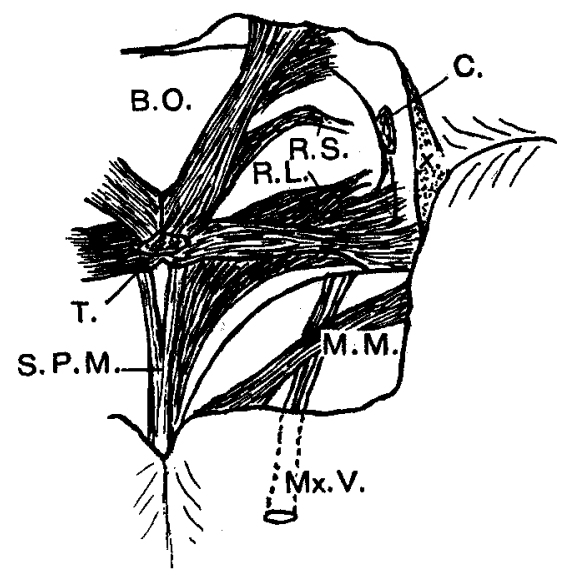

Fig. 9 Diagram of structures exposed in dissection of orbital fossa from above; second stratum. C., small opening in fornix conjunctivae; R.L., rectus lateralis muscle; S.P.M., superior postero-median muscular band; other lettering as in figure 8.

the median carotid artery were cut posteriorly and reflected forward to expose the muscular mass situated beneath (they are not represented in the figure).

From the median notch formed by the junction of the two maxillary elements there arises a thin muscular band which anteriorly becomes divided into two symmetrical halves as indicated in the diagram. It becomes inserted into the central tendinous mass. On reflecting this muscle forwards, another similar, though slightly larger, muscular band is seen lying immediately beneath it. (For the sake of convenience in description these muscles will be termed the superior and inferior 
postero-median muscular bands respectively). Its origin and insertion are similar to the first mentioned muscle and are shown in the next dissection.

Lateral to these muscular bands and situated on a lower plane, there is seen a broad sheet of muscular tissue whose fibers are more or less parallel to the anterior convex border of the maxillary element. The relations of this mass are more clearly brought out in the next dissection.

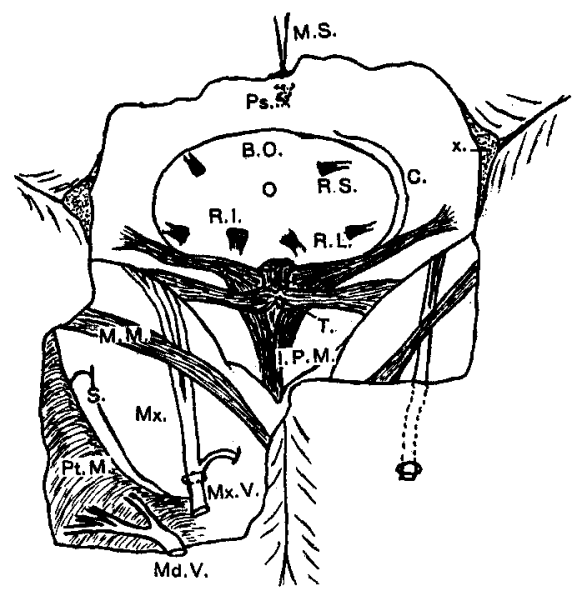

Fig. 10 Diagram of structures exposed in dissection of orbital fossa from above; third stratum. I.P.M., inferior postero-median muscular band; $M x$., maxillary element; $P$ s., point of attachment of proboscis; $P t . M$., muscular mass probably belonging to the pterygoid group; R.I., rectus inferior muscle; $S$, deep fossa behind maxillary element. Note: the arrangement of the muscle I.P.M. and the one overlying it is such as to suggest the use of the term 'retractor bulbi.' Other lettering as in figure 8 .

Third stratum (fig. 10). The entire muscular mass representing the levator palpebrae superioris and the superior portion of the postero-median muscular band were removed. The vessels and nerves were also removed with these. It was noted that a small branch of the ophthalmic artery entered the pulbus oculi in the mid-line at the lower margin of the fibrous optic nerve. With the exception of the rectus lateralis the muscular mass in relation to the eye received its innervation in a very irregular fashion from branches of the third nerve. The sixth nerve, as 
has already been noted, passed directly to the inferior surface of the latter muscle.

On the left side, the opening in the bony roof of the orbit was continued posteriorly and the floor of the middle fossa of the skull was removed to the level of the foramen ovale. It will be here noted that the whole extent of the upper surface of the left maxillary element is exposed, together with the maxillary division of the fifth nerve and its overlying muscular band. Posteriorly is seen a well marked deep fossa. The mandibular division of the fifth nerve divides into a number of branches which pass into a thick muscular mass which, as far as it can be judged from its location, probably represents some part of the pterygoid group.

Posteriorly in the orbital fossa is seen the inferior portion of the postero-median muscular band. Also at this level from the region of the central fibrous mass two muscular bands pass laterad to be inserted into the fibrous tissue on the anterior surface of the bony wall of the maxillary element. At a lower level in this region is seen a layer of muscle whose fibers have already been noted as coursing laterad parallel to the anterior convex border of the crypt. It is seen to have a somewhat wide origin in the mid-line below the central tendinous mass. As the fibers pass outwards they converge and are inserted into the deep fascia at the lateral margin of the orbital fossa.

Two muscles, which from their relations represent the inferior recti, pass almost directly downwards from the central tendon to their insertions on the bulbus. The insertions of the rectus superior and lateralis muscles are also indicated.

In the mid-line in front, the roof of the orbit has been dissected away to show the point of attachment of the proboscis and its relation to the eye.

The arrangement of the orbital contents throughout is very similar to that obtaining in the cyclopian eyes dissected by Wilder (28). As in his cases, the mesial recti muscles are absent owing to the complete suppression of the area in which they normally develop. The superior oblique muscle was not identified in this case. 


\section{MACROSCOPIC DESCRIPTION OF THE BRAIN}

For the sake of convenience in description the following terms have been made use of. Those structures which together form that portion of the brain anterior to the pineal region are collectively spoken of as the primary forebrain vesicle. The primary forebrain vesicle is further subdivided into an anterior cerebral vesicle or cerebrum, and a posterior thalamus or thalamic mass.

\section{Primary forebrain vesicle}

From above: As seen in figure 48, this region appears as a large unpaired vesicle having a smooth arched roof which extends caudad to a point immediately in front of the corpus pineale. At no point does it arch over the posterior brain segments.

From the side: In the lateral line is here seen a very distinct sulcus passing in a circumferential manner around the cerebral vesicle. Its origin is hidden posteriorly in a deep fissure which exists between the basal portion of the primary forebrain vesicle and the brain stem. The relation of this sulcus may be seen by comparing figures 48,49 and 50 . It sharply marks off the smooth bulging roof from the thickened and somewhat furrowed base.

From below: The general configuration of the inferior surface of the primary forebrain vesicle is well illustrated in figure 50. It is seen to be divided by a quite marked $\mathrm{Y}$-shaped furrow into two paired posterior lobes and a single azygos anterior lobe. This furrow cannot be compared with any sulci appearing on the surface of the normal cerebral hemisphere. It is apparently only the result of a mutual adaptation between the cerebral vesicle and the floor of the skull cavity. Smaller secondary furrows are seen on each of the lobes but the direction in each case is always at an angle to the main $\mathrm{Y}$-shaped furrow. Apparently these very shallow sulci are due mainly to the presence of blood vessels. In the azygos anterior lobe a small fossa is seen directly in front of the diverging limbs of the $Y$-shaped principal furrow.

There is no appearance whatever of olfactory lobes, optic nerves or tract, infundibulum, or in fact of any structure normally appearing in a basal view of this portion of the brain. 
As has been noted, the basal portion of the cerebrum, which posteriorly is more or less bilaterally symmetrical, is separated from the cerebellum by a very deep fossa.

From above on removal of the roof: On laying back the smooth, thin, arched roof, a cavity is brought to view which represents the dilated ventricular cavity of the primary forebrain. The floor of this cavity, which is quite vascular, is seen in figure 51 to be marked by a Y-shaped ridge which corresponds to the external furrow before mentioned. Overhanging somewhat the basal limb of this $Y$-shaped ridge posteriorly there is seen a smooth rounded protuberance of more or less pyriform outline. Subsequent examination has shown this to represent the only persisting portions of the thalamus. At its base this thalamic mass becomes flattened from within outward, and is continuous with the thickened basal portion of the cerebrum as seen in the diagram of the brain in sagittal section (fig. 11).

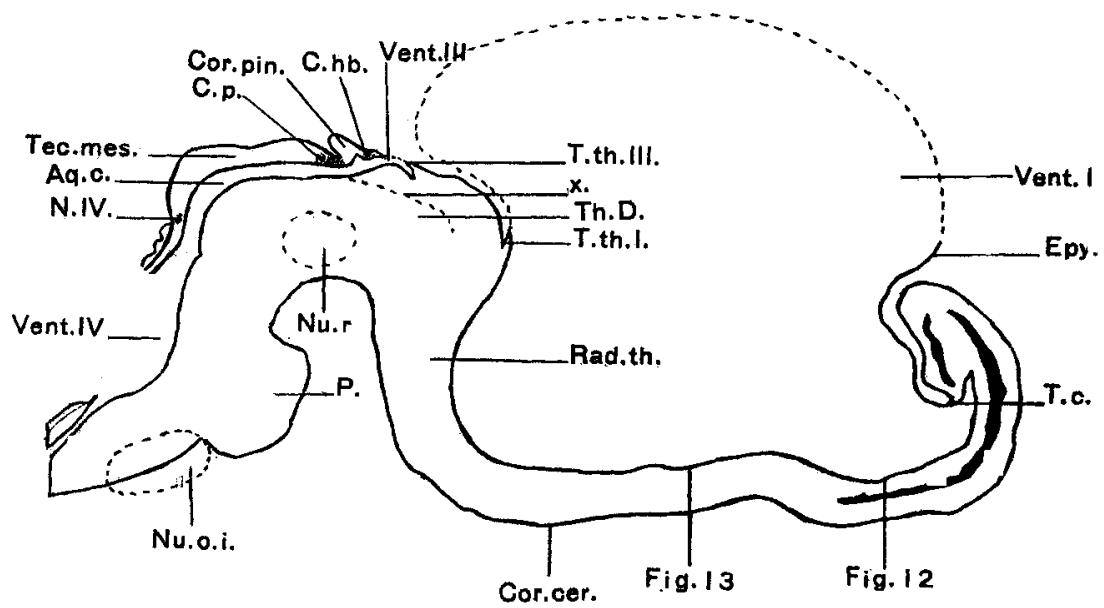

Fig. 11 .Diagrammatic medial sagittal section through the entire brain. The levels at which the following coronal sections (figs. 12 and 13) were taken are indicated. Aq.c., iter; C.hb., habenular commissure; Cor.cer., cortex cerebri; Cor.pin., pineal body; C.p., posterior commissure; N.IV., trochlear nerve; Nu.o.i, . inferior olive; $N u . r$. , red nucleus; $P$., pons; Rad.th., ventral thalamic radiations; $T . c$. , taenia cerebri, or point of attachment of thin cerebral roof $(E p y)$ to inner pillar of cerebral margin; Tec.Mes., midbrain roof; Th.D., dorsal thalamic mass; T.th.I., attachment of cerebral roof to thalamus; T.th.III., attachment of thin roof of third ventricle to thalamus; Vent.I., cerebral ventri sle; Vent.III., third ventricle; Vent.IV., fourth ventricle; $X$., ependymal diverticulum from iter. $\times \frac{2}{3}$. 
The roof, which is made up of ependyma, pia and fibrous tissue fused togeiner, is everywhere quite thin. Its relations to the thickened base are best brought out in the diagrams (figs. 11,12 and 13). These represent respectively a sagittal and two transverse sections of the brain.

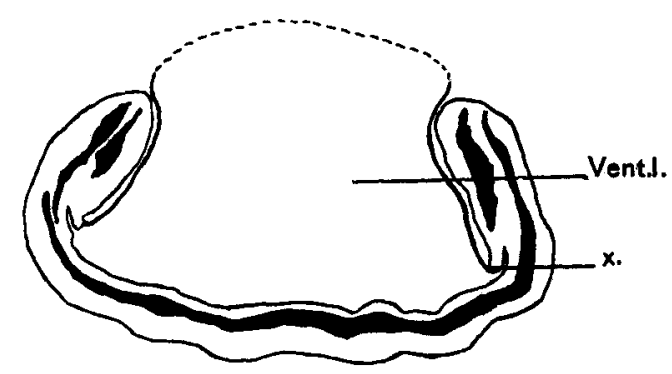

12

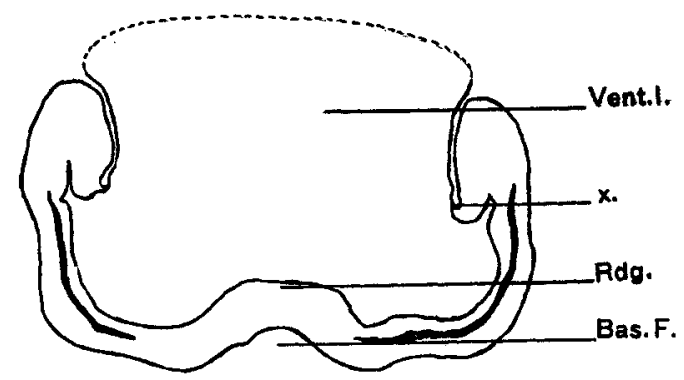

13

Fig. 12 Coronal section through fore-part of cerebral vesicle. Vent.I., cavity of cerebral vesicle; $X$., marks point of attachment of thin roof to inner pillar of thickened recurved cerebral margin. $\times \frac{2}{3}$.

Fig. 13 Coronal section through mid-part of cerebral vesicle. $R d g$. , ridge in ventricular cavity corresponding to external furrow (Bas.F.). The relations of this ridge and furrow are further illustrated in figures 50 and 51. Other letters as in figure 12. $\times \frac{2}{3}$.

It will be seen in these diagrams that the thickened basal portion of the cerebral vesicle presents an arched margin, and the roof is not attached to the apex of this arch but to the base of the inner pillar. This recurved margin subsequently has been identified as a modified hippocampal formation. Thus the point of attachment of the thin roof will represent the fimbria. 
The relation of this roof to the thalamic mass as subsequently determined may be seen by comparing a sagittal section (fig. 11) with a surface view from above and in front (fig. 14).

It will be seen that there is a discontinuity of the ventricular system in this region so that the large cavity of the primary fore brain vesicle is not in connection with the iter. The line of attachment of the thin roof to the surface of the thalamic mass

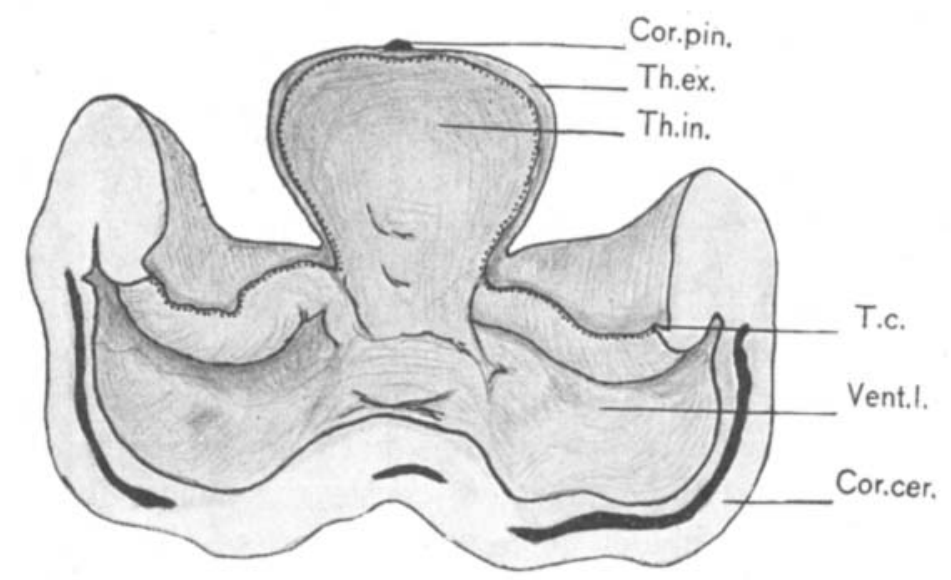

Fig. 14 Diagram of posterior portion of forebrain seen from above and in front. The thin roof has been removed and the point of its attachment to the cerebrum and thalamic mass is indicated in dotted lines. Cor.cer., cortex cerebri; Cor.pin., pineal body; T.c., taenia cerebri; Th.ex., extraventricular portion of the thalamus; Th.in., intraventricular portion of the thalamus; Vent.I., cavity of cerebral vesicle.

corresponds to the taenia thalami. The taeniae become continuous with one another some distance in front of the pineal body. At the point of junction between the thalamic mass and the cerebrum, the roof is attached to the margin of the latter structure and the taenia thalami becomes continuous with the fimbria.

In the diagrams (figs. 11, 12 and 13), the basal plate of the cerebrum is represented as split into two laminae. This splitting apparently occurred during fixation and the line of cleavage passes in most cases through the portion repesenting the medullary center. 
It is to be noted that the posterior poles of the so-called basal lobes of the cerebral vesicle project backward for a short distance on either side of the thalamic mass and peduncular region.

In connection with the foregoing description it must be borne in mind that beside the malformations which are the direct outcome of the cyclopic condition, others are present which are consequent on the internal hydrocephalus. It is to this factor that we must look for the cause of the marked dilatation of the forebrain vesicle with the bulging of its thin walled roof, and probably also for the lack of continuity in the ventricular system. These points will be more fully dealt with later.

\section{Brain stem and cerebellum}

The midbrain, as may be seen in figures 48 and 49 , is plainly visible from above and on account of its thick pial covering shows no external indications of division into corpora quadrigemina. The marked flexure which obtains between the primary forebrain vesicle and the brain stem causes the peduncular region to be completely hidden in a ventral view of the brain. No cerebral peduncles are present.

Both vermis and lateral lobes of the cerebellum are well developed. Their various subdivisions show but little departure from the normal. The pons, which cannot be distinctly seen in the figures on account of the marked flexure of the brain stem, is also well developed.

The absence of the pyramids and the great prominence of the olives are the only external features in which the medulla appears to vary from the normal. The attachments of the cranial nerves could not be made out in the gross as they had been removed, together with the vessels and pia, before the material came into my hands but subsequent to the drawings shown in figures 48 to 51 .

It is to be noted that the marked abnormal flexure of the brain stem in the region of the midbrain is apparently due to the nondevelopment of the cerebral peduncles. 


\section{TECHNIQUE}

Without further examination, the brain stem and thalamic mass were imbedded in celloidin. When this had been hardened sufficiently it was subdivided into blocks of convenient size and serial sections made 45 microns in thickness. Sections were selected at suitable intervals (about every tenth, but in places every fifth section) and stained by a modified Weigert method and counterstained with Upson's carmine. For comparison, a similar series was prepared from the brain stem and left cerebral hemisphere of a normal full term foetus.

Blocks also were cut from selected areas of the cortex of the cerebral vesicle and sections of various thicknesses were examined. For comparison, sections were studied from the cortex of the right cerebral hemisphere of the normal foetus mentioned above. In each case the following stains were used modified Weigert, modified Nissl, and a simple hematoxylin-eosin stain.

The drawings of the microscopic preparations from the brain stem and cerebral cortex have been made with the aid of a Leitz projectoscope.

\section{MICROSCOPIC DESCRIPTION OF THE BRAIN}

Brain stem and cerebellum (figs. 24 to 47)

On comparison with sections taken from the normal brain stem at birth, this series shows several outstanding points of difference. There is a complete absence of the crura cerebri in the midbrain, the fasciculi longitudinales pyramidales in the pons and the pyramids in the medulla. The marked S-shaped flexure of the brain stem causes sections, which are transverse to the long axes of the medulla and midbrain, to be oblique and horizontal in the intervening regions. There is also a marked deficiency in the number of well medullated fibers present throughout. The development of the myelin sheaths has evidently been retarded. In the region of the midbrain the pia has been greatly thickened and forms a thick capsule which entirely masked the surface markings over this area in the recent state. 
Cranial nerves. As has already been mentioned in the gross description, the olfactory bulbs and tracts are entirely wanting.

The optic nerve is represented by a few fibrous strands which pass from the bulbus oculi at the region of entrance of the central artery into the surrounding connective tissue of the orbit. As no microscopic examination was made of these, it is impossible to say whether any true nerve fibers were present. No connection existed between the eye and the central nervous system.

The deep connections of the cranial nerves from the oculomotor caudad are practically normal and will be but briefly noted here.

The oculomotor nerve (N.III, figs. 36 to 39 ) is essentially normal in its origin. Cephalad, the oculomotor nuclei (Nu.N.III) are in relation with a well marked nucleus of the posterior longitudinal bundle or nucleus of Darkschewitsch (Nu.f.l.m.). Some of the more caudal fibers of this nerve have a crossed relation. The emergent fascicles do not pierce the red nucleus but curve around its caudal and mesial surfaces.

The trochlear nerve (N.IV. figs. 32 to 35$)$, although very small, can be.made out readily. Its nucleus $(N u . N . I V)$ is in relation to the posterior longitudinal bundle and its root fibers pass towards the superior medullarv velum on the median aspect of the mesencephalic root of the trigeminal nerve. The decussation in the velum is quite normal.

The trigeminal nerve $(N . V)$ is normal and its relations are well brought out in figures 24 to 37 .

The abducent nerve (N.VI, figs. 32 to 36 ) shows no departure from the normal. The connection between its nucleus $(N u . N . V I)$ and the superior olive (Nu.o.s.) is also to be made out.

The facial nerve (N.VII, figs. 32 to 39 ) is normal in all its relations. The emergent fascicles on the right side are arranged around a small artery.

The vestibular nerve (N.VIII, vest., figs. 32 to 39 ) is normal in its relations and connections. The cochlear nerve (N.VIII, $c o c h)$ is also normal and the dorsal and ventral cochlear nuclei are quite evident (Nu.coch.d. and Nu.N.coch.). The corpus trapezoideum (c.t.), superior olive (Nu.o.s.) and lateral lemniscus (L.l.) are well shown, and the continuity of the superior olive with the 
nucleus of the lateral lemniscus (Nu.l.l.) is also apparent. The striae acusticae (s.a.) are but poorly medullated.

The glossopharyngeus and vagus nerves (N.IX and $X)$ together with the tractus solitarius (T.s.) nucleus alae cinereae (Nu.a.c.) and nucleus ambiguus (Nu.amo.), are shown in figures 27 to 32 .

The accessory nerve $(N . X I)$ shows a somewhat anomalous condition of development. But few fibers of its medullary portion could be distinguished on the left side. On the right, these fibers are grouped peripherally in a compact bundle which is well shown in figure 24, lying just within the ventral border of the substantia gelatinosa (s.g.). These fibers apparently take their origin from the central gray matter lateral to the central canal. No definite nucleus could be distinguished in this region but these fibers are clearly not related to the nucleus ambiguus; vide Cajal (3).

The hypoglossal nerve $(N . X I I)$ and its nucleus (Nu.N.XII) are normal in their relations. There is no sharp line of demarcation between the hypoglossal nucleus and the motor nuclei of the anterior horn in the upper cervical cord. The accessory nucleus of Roller is also to be made out.

Arcuate nuclei (Nu.a., figs. 25 to 34). These bodies are prominent in the lower medulla and are here somewhat larger than normal. On the appearance of the inferior olive, however, they diminish in size and at the level of the pons become continuous through the nucleus of the raphe with the nuclei pontis.

Inferior olive (Nu.o.i., figs. 27 to 35 ). These form very prominent projections on the ventral aspect of the medulla. They are somewhat larger than normal. As the series in this region was not absolutely complete, the exact antero-posterior diameter could not be determined but it would not be much less than $8 \mathrm{~mm}$. The greatest dorso-ventral diameter is $5.6 \mathrm{~mm}$ and the transverse diameter is $3.8 \mathrm{~mm}$. These dimensions in Sabin's model (20) were $7.5 \mathrm{~mm}$., $4.48 \mathrm{~mm}$., and $6.5 \mathrm{~mm}$., respectively. There has been, therefore, an increase of the dorso-ventral at the expense of the transverse diameter. This change of form is probably due to the absence of the pyramids. In transverse 
section it is seen that the olives differ from the normal in showing three very definite outpouchings-a dorsal, a ventral and a lateral. The fibers arising from the olive are quite lacking in myelin. The mesial and dorsal accessory olives are present ir practically normal relations.

Lemniscus system. The decussatio lemniscorum (Dec.l.), the stratum interolivare lemnisci (S.i.l.) and the mesial lemniscus (L.m.) up to the level of the anterior portion of the red nucleus $(N u . r$.$) are essentially normal. At about the caudal end of the$ nucleus ruber, a well marked strand of fibers is given off from the lateral part of the main sheet of the fillet. This has been identified as the superior lemniscus (L.s., fig. 39). It passes up to end in the region of the superior colliculus. Beyond the nucleus ruber the lemniscus cannot be traced as a definite fiber system. Here its fibers become scattered and are lost in the dorso-lateral portions of the thalamic mass.

Fasciculus longitudinalis medialis (F.l.m.). This fiber system is prominent throughout the series caudad to the posterior commissure. It is the most completely medullated tract in the brain stem and on this account can be easily separated from the lemniscus in the stratum interolivare. Its relations throughout are normal and it is traceable, together with fibers from the stratum album profundum of the midbrain, into the posterior commissure Above the oculomotor nucleus (Nu.N.III) it is related to a well developed nucleus (Ny.f.l.m., figs. 38 to 40 ) having the same relations as the nucleus of the posterior longitudinal bundle in normal sections (Darkschewitsch).

Corpus trapezoideum (C.t., figs. 35 to 37). The trapezoid body and the lateral lemniscus (L.l. figs. 33 to 37 ) together with their associated nuclei are quite normal in their relations and course. The lateral lemniscus terminates in the well marked nucleus of the inferior colliculus (Nu.c.i., figs. 33 to 36). No brachium of the inferior colliculus is present.

Cerebellum and peduncles. The cerebellum shows a well developed dentate nucleus (Nu.d.) together with globose (Nu.g., figs. 31 to 32 ) emboliform (Nu.emb., figs. 32 to 34 ) and roof nuclei. There are almost no medullated fibers to be found in the 
cerebellum other than those entering by way of the corpus restiforme (C.r., figs. 27 to 37 ) and those arising in the dentate nucleus. Even the medullary center of the flocculus is lacking in myelin, whereas in the normal term foetus this area is usually well medullated.

The relations of the cerebellar peduncles are essentially normal. The corpus restiforme is but slightly medullated and shows a very distinct and circumscribed nucleus (Nu.c.r., figs. 34 to 35) after its entrance into the cerebellum. The pons, which is well developed, contains no medullated fibers. The brachia conjunctiva (Br.c., figs. 32 to 37 ) are readily distinguished, arising in the nucleus dentatus and coursing ventrad and cephalad to decussate caudad to the red nucleus. Their fibers are poorly medullated.

Nucleus ruber (Nu.r., figs. 37 to 42 ). The red nucleus is well formed and prominent in the midbrain region. Owing to the absence of the crusta and also of a well marked substantia nigra, this nucleus is only separated from the periphery by a very short distance. It is to be noted that the emergent fibers of the oculomotor nerve do not at any point pierce the substance of the red nucleus as they do in the majority of cases normally. The cephalic end of this nucleus is in relation with the lateral nucleus of the thalamic mass.

Superior colliculi (C.s., figs. 35 to 39). These form prominent projections which are completely covered over by a thickened layer of pia $(P$., figs. 31 to 46 ) which surrounds the midbrain region. The cellular elements are but poorly differentiated. A few medullated commissural fibers pass across the mid-dorsal line above the stratum album profundum (s.a.p.). In the midline dorsal to the aqueductus (Aq.c.) in this region there is a well marked oval mass of embryonal cells $(\mathrm{Ng}$., figs. 36 to 39 ).

The dorsal tegmental decussation of Meynert (D.t.d.M., fig. 37 ) is well shown ventral to the oculomotor nuclei. The ventral tegmental decussation was also distinguished but is not shown in the figures.

Fasciculus retroflexus of Meynert (F.r.M., figs. 38 to 46). This bundle forms a prominent landmark in the region of junc- 
tion between the midbrain and diencephalon. The corpora habenulae are not well developed, but on each side their site is marked by the beginning of the fasciculus retroflexus. The bundle passes down and comes into relation with the dorso-mesial surface of the red nucleus. From this point onwards it is applied to the mesial surface of this nucleus in its course to the ganglion interpedunculare. At no point does the fasciculus pierce the red nucleus. Throughout the major part of its course this bundle is accompanied by a small collection of gray matter, as is usually the case, normally. The ganglion interpedunculare consists of a somewhat diffuse collection of cells between and ventral to the red nuclei toward their caudal ends.

\section{Thalamic mass}

Cephalad to the red nucleus there is found a large irregularly arranged nuclear mass, in the lateral portions of which the lemniscus medialis becomes lost. This area may be roughly divided into a dorsal cellular portion and a ventral fibrillar area.

The dorsal cellular area. Posteriorly, the habenular bodies $(N u . h b$., figs. 44 to 46$)$ may be distinguished, together with the fibers of the fasciculus retroflexus of Meynert which arise in these nuclei.

The cells making up the thalamic nuclei are of two varieties:

$a$. Both large and medium sized, well developed multipolar cells whose cytoplasm takes the carmine stain deeply and which do not differ in any marked degree from those found in the pulvinar of the normal thalamus.

$b$. Scattered between these large cells are numerous small embryonic or neuroglial elements, having a small amount of cytoplasm which does not take the carmine stain deeply. These cells are far more numerous than the large multipolar variety, and are found both in the dorsal nuclear portion of the thalamus and in the ventral field, though far more abundant in the former area. The large cells, on the contrary, are almost entirely confined to the dorsal nuclear area.

These cellular elements are arranged in irregular groups so that it is possible to distinguish certain irregularly arranged nuclei in the dorsal area. 
In the anterior portion, the dorsal area is divided into two large irregular lateral nuclei (Nu.lat.Th., figs. 41 to 46 ) and a smaller mesial nucleus (Nu.med.Th.).

Caudally the lateral nuclei are further subdivided so that it is possible to distinguish three nuclei in this region. These may be termed for descriptive purposes, dorsal (Nu.lat.1), lateral (Nu.lat.2), and central (Nu.lat.3) nuclei of the lateral mass. The mesial nucleus $(\mathrm{Nu.Med.Th.}$ ) is present in the caudal portion in essentially similar relations.

It is to be noted that these thalamic nuclei do not come into relation with the cortex cerebri at the junction of the thalamic mass and the cerebral vesicle, but are separated from it by the ventral thalamic radiation.

The ventral fibrillar area. This area occupies but a small space in sections through the more caudal part of this region, but increases in size as one passes forward by the addition of fibers arising in the dorsally placed nuclei. It is made up of a complex of both medullated and nonmedullated nerve fibers, which, in the caudal portion, are twisted into irregular whorls and tangles. It is remarkable that, in this region, irregular strands of poorly medullated fibers may be seen in numerous places piercing the outer limiting layer of neuroglia in the ventral region and ramifying within the thickened pia ( $\beta$, figs. 42 to 44 ).

Passing forward, the thalamic mass becomes united to the cerebral vesicle by a narrow peduncle. This peduncle is seen to be made up almost entirely of ventrally coursing fibers continuous posteriorly with those of the ventral area of the thalamic mass. These fibers must be taken to represent an atypically developed thalamic radiation ( $R a d . T h$., figs. 41 to 47 ).

The major portion of the fibers of the thalamic radiation are applied to the ventral surface of the cerebral vesicle on which they rapidly spread out and come to an end. The ventral surface of the cerebral vesicle represents the free surface of the cortex. Thus most of the fibers ar sing in the thalamic mass ( $R$ ad. $T h$.$) pass directly into the zonal or plexiform layer of the cere-$ bral cortex (St.z., figs. 46 to 47 ). 


\section{Cerebral vesicle}

There is no appearance whatever of corpus striatum, rhinencephalon, or in fact of any of the structures developed ventral to the recessus neuroporicus in this region under normal circumstances. The term 'rhinencephalon' is here used to indicate the basal structures of the forebrain in most intimate connection with the olfactory nerve and does not include pallial olfactory centers. It is only for the sake of convenience in the present description that $I$ consider myself justified in employing the term rhinencephalon in this fashion; for when used in the above sense it effectually defines the limits of those areas which are quite absent from this brain.

Cortex cerebri. The basal portion of the cerebral vesicle varies in thickness from about $10 \mathrm{~mm}$. at its thickest at the point of entrance of the thalamic radiations, to about $5 \mathrm{~mm}$. at its thinnest. The cortex shows well developed cell lamination, and the types of lamination vary in different regions. It is impossible, however, to identify these areas as representing any of the histologically differentiated regions to be found in the normal cortex at birth.

There is practically no medullated tissue to be found throughout the cortex. Indeed, the only area in which it is prominent at all is at the point of entrance of the thalamic radiations. In this region in figures 46 and 47 , the cortex of the left posterior pole is shown cut tangentially. In the second layer of the cortex here, numerous groups of cells (C.isl.) disposed in irregular, more or less circumscribed areas, are to be noted. These islands are made up of two kinds of cells; (a) very numerous, small, embryonic elements, and (b) large polymorphic multipolar cells. In figure 15 this arrangement is brought out in transverse section. Only over this area of the cortex in this specimen were these large polymorphic elements to be found predominating in the stratum which is normally the layer of small pyramids. It would thus appear that the presence of the fibers of the atypical thalamic radiation has exerted an influence upon the growth of these neurones. Just what connection, if any, exists between these cells and the thalamic fibers could not be ascertained. The tis- 
sue was not in a favorable condition for metallic impregnation and, although numerous attempts were made, no successful preparations were obtained.

Everywhere in this case the cortex is markedly thickened. The thickest cortex at birth (at least in the case I have used as control) is over the central area. Here the cortex is about $2 \mathrm{~mm}$. in thickness, while the thinnest cortex in the cyclopian foetus measures $3 \mathrm{~mm}$. or more, the line of demarcation between cortex and medulla being very indefinite. The thickening is mostly the result of an increase in the deep polymorphic layer of cells, although all layers show an increased thickness.

When examined at a low magnification the wall of the cerebrum is everywhere seen to be divisible roughly into five strata. This lamination is illustrated somewhat diagramatically in figure 18 . The strata appear as follows: (1) an outer layer comparatively free from cells and varying in thickness in different areas, (2) a stratum rich in cells but whose elements tend to become arranged in arge irregular groups (3) a layer of densely packed cells, (4) a layer whose cellular elements resemble somewhat in arrangement those of the second stratum, and (5) a layer representing the medullary center.

For a more detailed description, sections have been selected from two histologically distinct areas of the cortex (figs. 15 and 16). Figure 17 shows a section through the precentral area in a normal full term foetus for comparison as to thickness and general arrangement of elements. These drawings were made with the aid of a Leitz projectoscope and are each at a magnification of 65 diameters.

Figure 15 has already been referred to and is a section taken through the cortex near the junction of the thalamus and cerebral vesicle. The plexiform layer (I) at its periphery shows an irregular layer of embryonic, or more probably neuroglia, elements. Into this plexiform layer stream thalamic fibers. The boundary between layer (I) and the next stratum (II) is not sharp. In the second stratum (II) occur the groups of large polymorphic elements mentioned above. The third layer (III) is made up of medium and small pyramidal cells and embryonic elements. It is slightly thicker than layers I and II combined 
and the average size of its cell elements become progressively smaller from without inwards. The fourth or polymorphic layer (IV) in the figure appears to be further subdivided into a more superficial zone of scattered small cells and a deeper more compact zone This is not the case, however, and this appearance is due to some of the elements in this layer being arranged in groups of irregular size, the cells in which are more closely packed than in the intervening spaces. Only a portion of one of these groups appears in the drawing and included in it are shown several very large well developed pyramidal cells. These large pyramidal cells occur singly or in groups over this area and are situated at about the level of the middle trisection of the polymorphic layer. The whole depth of this layer is not shown in the figure. The cells referred to exceed in size the largest cells found $n$ the normal foetal cortex used as control.

Figure 16 is taken from the so-called anter or lobe of the cerebral vesicle at a point about an inch from the arched margin of the same in the mid-line. The plexiform layer (I) is here quite sharply marked off from the subjacent cell layer. In this layer (II) the elements are somewhat closely packed and arranged in irregular groups. It varies considerably in thickness at different points at the expense of layer III. In the latter layer the arrangement of cells is somewhat looser and it apparently corresponds to Bolton's fourth layer or inner fiber lamina (2). Layer IV is made of closely packed small cells having a quite characteristic embryonic arrangement in the form of irregular rows at right angles to the surface of the cortex. The line of demarcation between this layer and the preceding one is very easily made out and in places is a'most as sharp as that between the plexiform layer and layer II. Layer V, the whole thickness of which is not shown in the figure, is the thickest of the cortical laminae, and combined with layer IV makes up more than one-half of the total thickness of the cortex. Its cel's are arranged in a

Fig. 15 Cyclopian cortex cerebri. Section taken from the region of junction of the cerebral vesicle and the thalamus. Explanation in text (page 223). $\times 65$.

Fig. 16 Cyclopian cortex cerebri. Section taken from the 'anterior lobe.' Explanation in text. $\times 65$. 

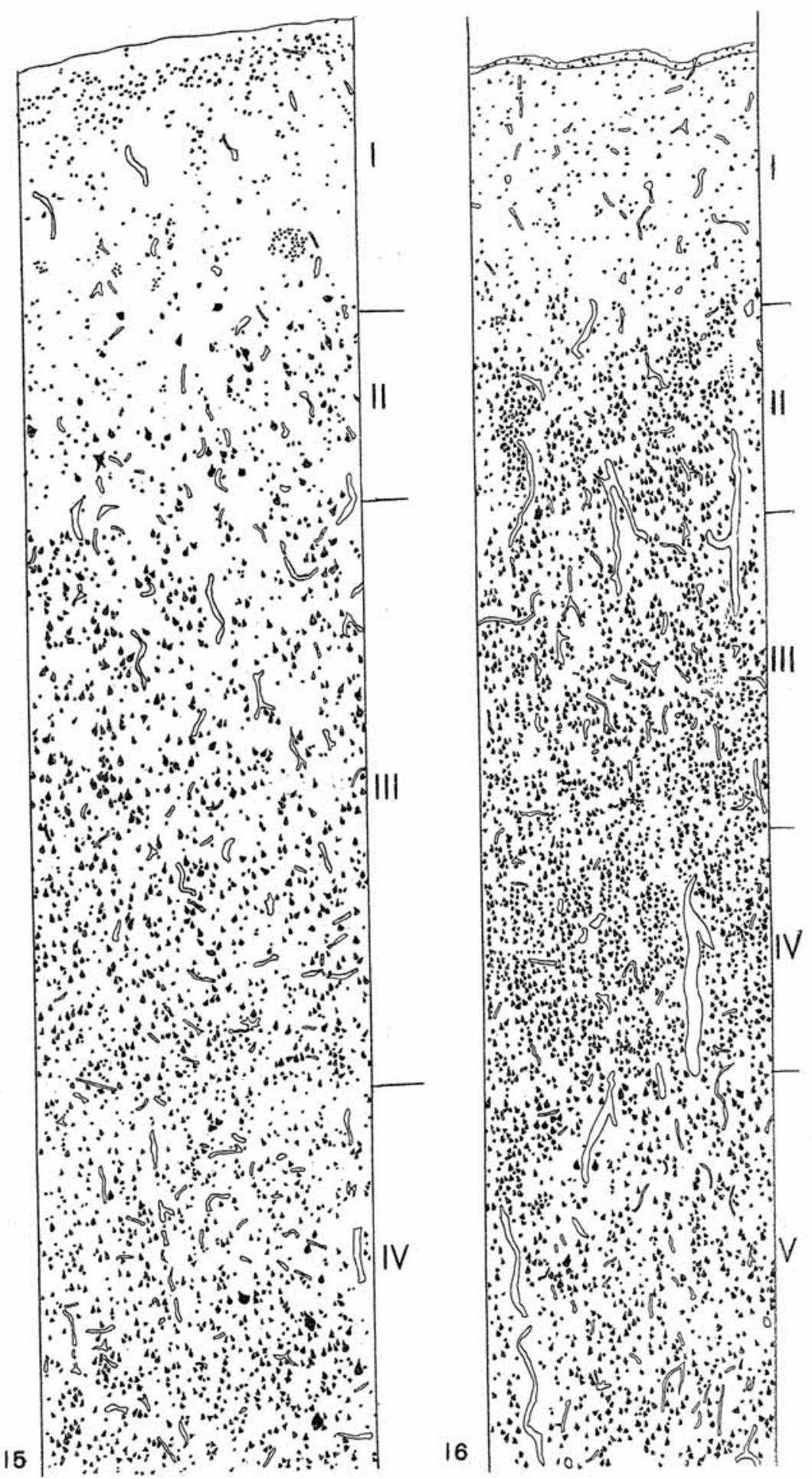


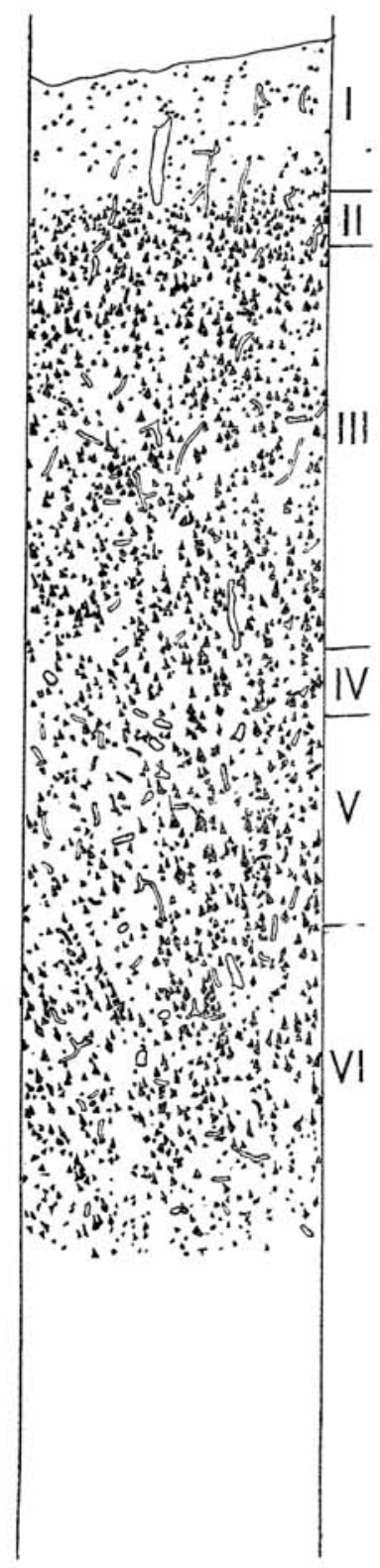

Fig. 17 Cortex cerebri of normal term foetus. Area precentralis $B$ (Elliot Smith). $I$., plexiform layer; $I I$., small pyramid layer, the cells here are small and many are quite embryonic; $I I I$., layer of medium and large pyramids; $I V$., granule layer which is a very thin and indistinct lamina; $V$, Betz cell layer; $V I$, polymorphic layer. $\times 65$. 
scattered fashion and occasionally form irregular groups of various sizes. There are no giant cells in this stratum over this area of the cortex.

The blood supply of the cyclopian cortex, as evidenced by the size and number of blood vessels, seems to be quite as rich as is the case normally.

With regard to the atypical course of the thalamic projection fibers it is to be noted that their presence in the plexiform layer is only the result of the altered relations between the pallium and the thalamus. Normally in mammals the thalamic fibers, to reach the pyramidal dendrites, must traverse the cortex from within outwards. Harrison (10) has shown that nerve processes wil develop readily even when the neurone is situated in an entirely strange environment. Under the altered form relations, then, in this case it is but natural that these fibers should still retain their growth energy and pass ventrad along the only course open to them to gain the cerebrum (figs. 46 and 47). On reaching the latter, they mostly take the shortest way available by which they can reach the dendritic processes of the pyramidal elements, namely, by coursing in the zonal layer. The apparent influence of this contact has already been noted.

It is of interest to note here that the passage of both efferent and afferent projection fibers in the plexiform or zonal layer of the cortex is the normal condition obtain ng in Amphibia. In these forms the zonal layer represents the only white layer of the cortex visible in transverse section (4). The cortical neurones occupy the space between the zonal layer and the ependyma. Their axones curve outwards to reach the peripheral white matter, while their dendrites come into contact with the afferent projection fibers in this layer also.

In the more caudal portions of the thalamus are found numerous fibers which in view of crowding have been unable to reach the cerebrum. Even under such adverse conditions the growth of these fibers was not arrested. They are here woven together into knots and tangles, and numbers of them have already been described as even piercing the limiting layer of neuroglia and ramifying in the pia ( $\beta$ figs. 42 to 44 ). 
Owing to the great modification of cell lamination brought about by the presence of thalamic projection fibers in the plexiform layer of the cortex in certain regions, it is not considered advisable to attempt to compare in detail the type of lamination found in such regions with that normally occurring in the developing cortex. In areas remote from such disturbing influences, however, such comparison may, I think, be safely made.

In figure 16 it was noted that layer III apparently corresponded to Bolton's inner fiber lamina (2). The inner fiber lamina in the normal developing cortex is a layer which develops as the result of a separation of the cortical neuroblasts into an outer and an inner cell lamina. The polymorphic layer of the normal adult cortex is derived from the inner cell lamina, while practically the whole cortex above the inner line of Baillarger is derived from the laminae superficial to this. If, then, layer III represents the inner fiber lamina, it would appear that the outer layers of the cortex in this case are in a state of sub-evolution. For the total thickness of layers I to III inclusive is less than that of the much thickened polymorphic layer (IV and V). The somewhat closely packed lamina of cells constituting layer IV, which is well developed over most areas of this cortex, appears to be peculiar to this case and not comparable to any layer normally present at term. In the case reported by Naegeli (17) however, a layer of apparently similar nature is shown in his figure 42. It would thus seem that the cortex had begun its development from within outwards in this region, as is normally the case.

At first sight it appears difficult to account for the greatly increased thickness of the cortex in a cerebrum in which cell differentiation has been described as subnormal. This difficulty is only an apparent one for, as will be subsequently pointed out, there is evidence in this brain to show that at least the greater part of the undifferentiated normal pallial anlagen are present. The surface area of the cortex, however, has not been increased by the formation of cerebral convolutions. Thus a large number of cell elements have to accommodate themselves over a limited area, resulting in the increased thickness of the cortex which 
otherwise is characterized by subnormal development. As will be subsequently noted in a future communication, there are reasons for regarding this thickening in some areas as being also partly due to hyperplasia.

Under normal circumstances Bolton (2) has pointed out that the cells in the cortex of the term child are less crowded than are those in the cortex of the developing foetus. As an important factor in reducing this aggregation of cells he points to the increased superficial area of the cortex at term due to the maturing convolutional pattern, "and the consequent smaller number of cells in a section of the same thickness."

Bolton and Moyes (3) have shown that the first large well developed cells in the cortex are the Betz cells and that these are prominent as early as the eighteenth week of foetal life. They are situated in the basal portion of the inner fiber layer. These authors also express an opinion that the sensory or afferent fibers to the cortex are in all probability developed before the motor or efferent fibers from the cortex.

In this case it has been shown that in those areas reached by the thalamic fibers, there is a marked tendency toward atypical overgrowth in certain neurones of the superficial layers with which these fibers come in contact. The presence of afferent fibers thus influences the growth of cortical neurones. Ordinarily these afferent fibers must enter through the basal portion of the cortex. It is in this basal portion of the cortex that the first well differentiated neurones appear and it is the basal laminae of the cortex that are the first to be evolved. It would be interesting to determine how far the tardy ontogenetic development obtaining over some areas of the normal cortex were dependent upon the late appearance in these areas of afferent projection fibers.

Naegeli (17) has described numerous well developed pyramidal cells in the cortex in his case, which have attained a considerable degree of differentiation and are possessed of short axone processes but which do not come into relation with any projection fibers from the thalamus, none of which, he says, gained the cerebrum. He has termed this growth process 'self-differentia- 
tion,' as opposed to 'dependent differentiation,' using the terms suggested, as he says, by Roux (19).

In this case, in some of the more basal portions of the cortex which are lacking in medullated fibers of thalamic origin, there are found in the deeper strata numerous giant pyramidal elements. These cells are much larger than any similar elements to be found in the normal new-born cortex, and each possesses a large vesicular nucleus with well developed karyosomes, while in the cytoplasm Nissl bodies are well formed and prominent. Although no medullated fibers of thalamic origin could be made out in such sections, it is very doubtful if these large elements can be considered as cells showing only 'self-differentiation;' they are probably influenced by non-medullated afferent fibers. On the other hand, in areas quite removed from possible thalamic influence as for example, the anterior portion of the rim of the cerebral cup, the smaller, more numerous and generally under-developed elements, making up the thickness of the cortex may, I think, be classed as 'self-differentiated,' in the sense of Roux.

The giant cells referred to in the preceding paragraph, which are located in the deep cell lamina of the cortex, are strikingly like the large efferent perikaryons described as Betz cells in the normal cortex of mammals. It has been shown by Bolton (3) that in the evolution of the cortex, those laminae situated above the level of the Betz cells, are the site of greatest differentiation and growth in the higher mammals and man. It thus happens that the increased cortical thickness causes these large efferent cells to lie more deeply in the human cortex than in that of lower forms. If then the giant cells in this cyclopian cortex represent the cell bodies of potential efferent neurones of the Betz type, the location at such a cortical level would be a further argument against any theory of phylogenetic reversion. An accurate knowledge of the number, arrangement and distribution of these cells would aid in determining how far such a comparison as the above is justified. In the event of the presence of sufficiently differentiated cortical tissue in any of the other cases of cyclopia at present in my possession, a complete topographical survey of such will be made. It would also be of interest to note what 
relation exists between the development of the corpus striatum when present, and such efferent neurones as those under discussion.

One other point may here be noted in connection with the examination of this cortex. It has been found that the character of the lamination, the thickness of the cortex and the condition of cell development, vary in different regions. Two of these histologically distinct areas are illustrated in the figures. It would seem that these areas are not sharply marked off from each other but are separated by transitional zones. However, as no complete topographical survey was made, this point was not definitely determined. Thus, histologically distinct areas are present but, with the exception of the dentate and fimbriodentate fissures, there is a complete absence of true sulci. This, then, is further evidence, it would seem, of the truth which Bolton has pointed out, namely, that the development of the convolutional pattern is secondary to the differentiation of the cortex into histologically distinct areas.

Cerebral limbi. At the base of the inner pillar of the thickened recurved margin of the cerebral vesicle, the thin roof becomes attached to the edge of the cortex. The relations of the roof in this region have already been noted in the gross description (figs. 11 to 13). Sections were made at intervals along this margin and the relations of the cerebral limbi studied. Drawings of three of these sections are here reproduced. Figure 18 is a section taken in the mid-sagittal plane; figure 19 is a section taken at the junction of the anteror and middle thirds, and figure 20 a section at the junction of the middle and posterior thirds of the left cerebral margin. The outlines of these drawings were made with the aid of a Leitz projectoscope and at the same time lines were drawn marking off the various cell laminae of the cortex. The spaces between these lines were subsequently shaded in free hand, so the details of cell arrangement are only indicated in a somewhat diagrammatic fashion. However, the relative thickness of the cortex and the arrangement of its various strata, as seen under low magnification, are fairly accurately shown. 


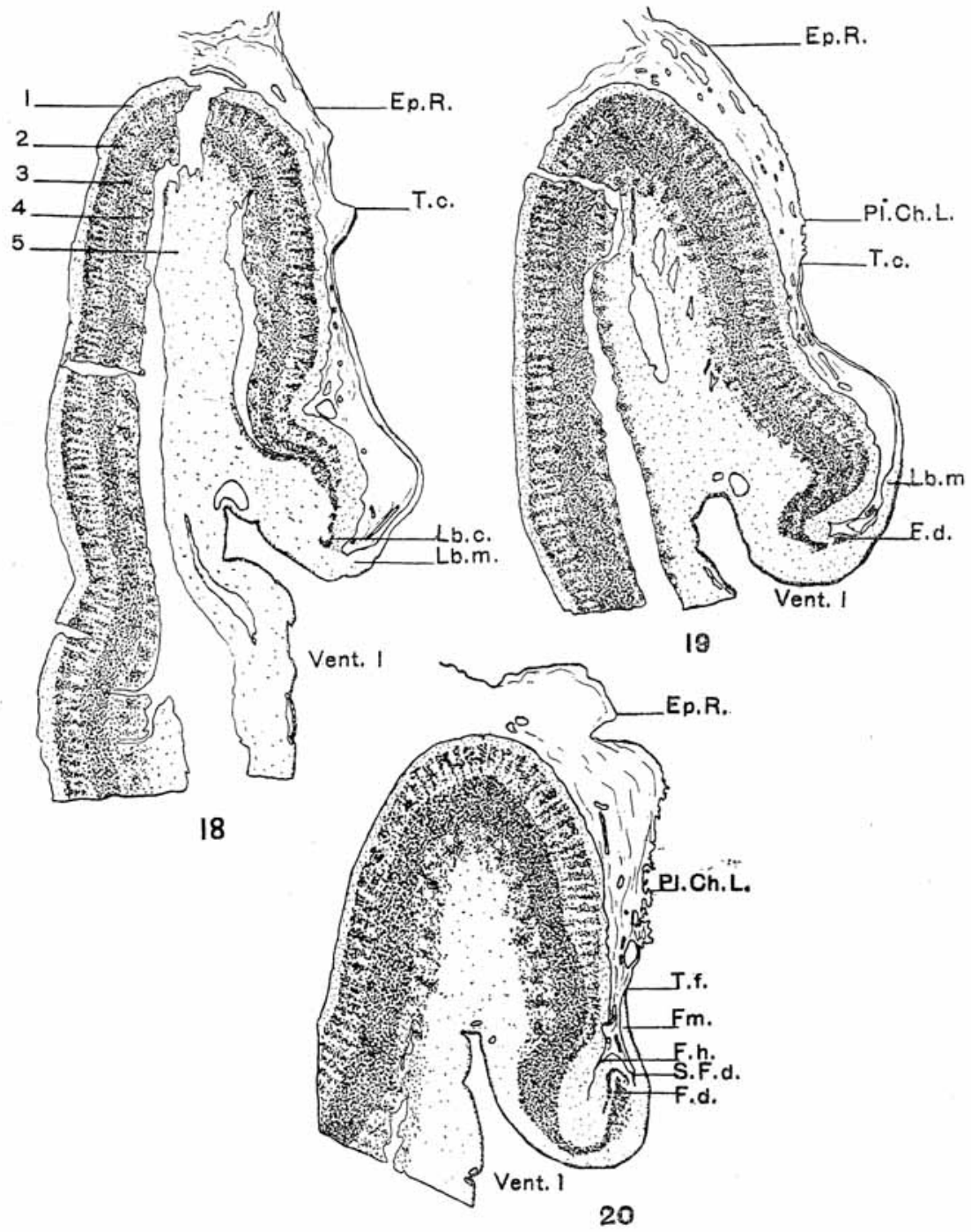

Fig. 18 Section through cerebral margin in mid-sagittal plane. Ep.R., ependymal roof; Lb.c., limbus corticalis; $L b . m$., limbus medularis; T.c., taenia cerebri; Vent.I., cavity of cerebral vesicle. Nos. 1 to 5, cortical laminas, explanation in text (page 231). $\times 3.5$.

Fig. 19 Section through cerebral margin in plane of junction of anterior and middle thirds of lateral rim. F.d., fascia dentata: Pl.Ch.L., choroid plexus. Other letters as in figure $18 . \times 3.5$.

Fig. 20 Section through cerebral margin in plane junction of middle and posterior thirds of lateral rim. $F . d$., fascia dentata; $F . h$., hippocampal fissure; $F m$., fimbria; S.F.d., fimbrio-dentate sulcus; T.f., taenia fimbriae. Other letters as in figure $18 . \times 3.5$. 
The major portion of the posterior two-thirds of the cerebral rim on both sides has been found to represent a but slightly modified hippocampal formation (fig. 20). The line of attachment of the thin roof (Ep.R.) corresponds to the edge of the limbus medullaris or fimbria $(F m$.). A well marked fascia dentata $(F . d$.$) is present, bounded laterally by the fissura hippocampi$ $(F . h$.$) , and mesially by the fimbrio-dentate sulcus (S.F.d.).$ Above the fimbria, the thin roof is invaginated by vascular tissue to form a band of choroid plexus (Pl.Ch.L.). This 'choriogenous zone' extends forward only as far as the extreme anterior tip of the fascia dentata (F.d., fig. 19). It is to be noted that if the normal lateral plexus could be straightened out it would represent an area such as is found here and bearing precisely similar relations to the fimbria.

Throughout the major portion of the anterior third of the cerebral rim, the fascia dentata can not be made out. Here the limbus corticalis has not become rolled upon itself (Lb.C., fig. 18). The limbus medullaris (Lb.M.) becomes on this account more extensive. No choroid invaginations are present over this area.

The identity of the limbus corticalis between the anterior extremities of the two definitely identified hippocampal areas is as yet obscure. It is hoped that further study in comparison with the other cases in my hands may clear up this point.

As has already been mentioned, no medullated fibers are present in this area of the cortex. In this connection it is to be noted that there was a complete absence of medullated tissue throughout the hippocampal area in the normal term foetus used as control.

\section{Ventricular anomalies}

The cavity of the fourth ventricle (Vent. IV) is essentially normal in its relations. It is lined throughout by a well developed layer of ependyma.

Turning now to the aqueductus (Aq.C., figs. 34 to 42 ), it is to be noted that numerous irregular ependymal diverticula arise from its ventral and lateral walls in the region just caudal to the posterior commissure. One of these evaginations passes 
ventrad and cephalad for a considerable distance and may be traced into the mesial thalamic nucleus ( $X$, figs. 42 to 47 ).

Just cephalad to the posterior commissure the pineal recess may be distinguished, and in front of this a few fine medullated fibers cross in the thin roof and constitute the habenular commissure (C.hb., fig. 44).

Immediately cephalad to the habenular commissure, the taenia thalami (T.th.III, fig. 45) is to be seen and two small areas of choroid plexus (Pl.Ch.III, figs. 44 to 45) project into the small ventricular cavity (Vent. III, figs. 44 to 46). Separating these two plexuses is a slightly thickened area in the roof representing the attachment of the anterior limb (dorsal) of the pineal. stalk.

In front of this the thin roof of the ventricular cavity has been torn away for a short distance and its relations cannot be accurately followed. However, the roof appears again in the sections somewhat more cephalad and is now seen to be thickened and lacking in choroidal invaginations. Traced forward from this region, the ventricle is seen to end blindly in the dorsal part of the thalamic mass.

It was noted in the gross description that the thalamic mass projected into the cavity of the primary forebrain vesicle and was covered with ependyma. From a study of the sections in this region it now appears that the line of attachment of this ependyma, or rather the line of its reflexion from the surface of the thalamus, approximately coincides with the line of demarcation between the dorsal nuclear mass and the ventral fibrillar area. Thus the greater part of the thalamic mass is extraventricular and is covered by a thick layer of pia and fibrous tissue. The taenia thalami (T.th.III), noted just in front of the pineal region, is not continuous with the taenia (T.th. I, figs. 45 to 47) over the anterior part of the thalamus to which the thin roof of the forebrain vesicle is attached. These relations are best seen in the diagram of a mesial sagittal section of the brain (fig. 11).

It is thus seen that there is a discontinuity in the ventricular system of the brain and that this interruption occurs in the region 
of the third ventricle (figs. 11 and 23). This obliteration of a part of the ventricular cavity is not necessarily the result of the growth conditions producing cyclopia; but probably these growth conditions rendered such an obliteration more liable to occur in this region than elsewhere.

\section{Mechanical considerations}

Stockard has shown that the condition of cyclopia may be produced at will in fish embryos in a high percentage of cases by treating the eggs with $\mathrm{MgCl}_{2}$ or $\mathrm{Mg}\left(\mathrm{NO}_{3}\right)_{2}$ solutions (24 and 26). He was thus able to study histologically a great number of cases in fish embryos otherwise perfectly normal. His observations showed that "the cyclopian defect is present from the first in the same condition that it will continue throughout development" (25). This statement was subsequently (27) somewhat modified by further experimental work, for it was found that cyclopia could be produced in a small percentage of cases by the action of magnesium chloride, even after segmentation had gone as far as the periblast stage (15 hours). Eggs older than the fifteen-hour stage were not affected by the $\mathrm{Mg}$ solutions. Thus, although cyclopia is not necessarily of germinal origin, the growth inhibition begins at so early a stage of embryonic life that it practically amounts to absence of certain areas during development. In other words, cyclopia is not the result of fusion of parts originally separate, but is due to absence during development of certain parts normally separating the eye anlagen.

Cyclopian monsters belong to that class of bilaterally symmetrical beings which have been termed by Wilder (28) 'cosmobia.' Development in these cases proceeds in a orderly fashion until some mechanical difficulty arises which cannot be overcome by the individual and death results. In fish the development in cyclopian forms goes on until the yolk supply is entirely used up, when the animal dies of starvation unless suitable food is artificially provided. In this connection it is also of interest to note that the absence of tissue anlagen does not postulate a nonfunctional nervous system, for individuals which have been kept alive and observed, reacted to stimuli in a quite normal fashion. 
In cyclopian mammals no mechanical difficulties incompatible with life are met until after birth. The animal then usually dies in a short time from interference with feeding and respiratory functions.

Thus, bearing in mind that the cosmobion is governed in all its growth changes by quite definite mechanical laws, an attempt may be made to interpret the form relations in this case. Certain areas have been practically absent during development. If one removed such areas from a model of a very young normal brain and approximated the cut edges, would the resulting malformation be similar to the case in hand?

If one examine one of His' models of the brain at the end of the fourth week, it will be seen that the telencephalon is represented by an expanded, thin walled unpaired vesicle, for at this stage the median furrow between the two pallial expansions is not developed. Looking at a mesial sagittal section through such a model, it is possible to mark out on the ventricular surface, with a considerable degree of accuracy, the areas which will later be developed into the corpus striatum and rhinencephalon, the pars optica and the pars mammillaris hypothalami, and the pallium (fig. 21).

It has been shown that in the present case, the pallium alone of these parts is present. Thus, if one cuts out fromboth sides of a clay model of the brain at the end of the fourth week, these areas which are not developed, and places the two halves remaining in apposition, then by simply pressing the cut surfaces of each half together one has reproduced in all its essentials the form relations obtaining in this cyclopian brain (fig. 22). It must be borne in mind, however, that this is reversing the true sequence of events.

We are left with a cup whose thickened walls are formed by all the pallium, and whose rim is formed by the two original mesial edges, to which of course is attached the much stretched thin roof. These mesial edges in the normal pallium for the most part are the areas in which the hippocampal formations are laid down. It is also along these mesial edges that the lateral choroid plexuses are normally invaginated. So in this case, we 

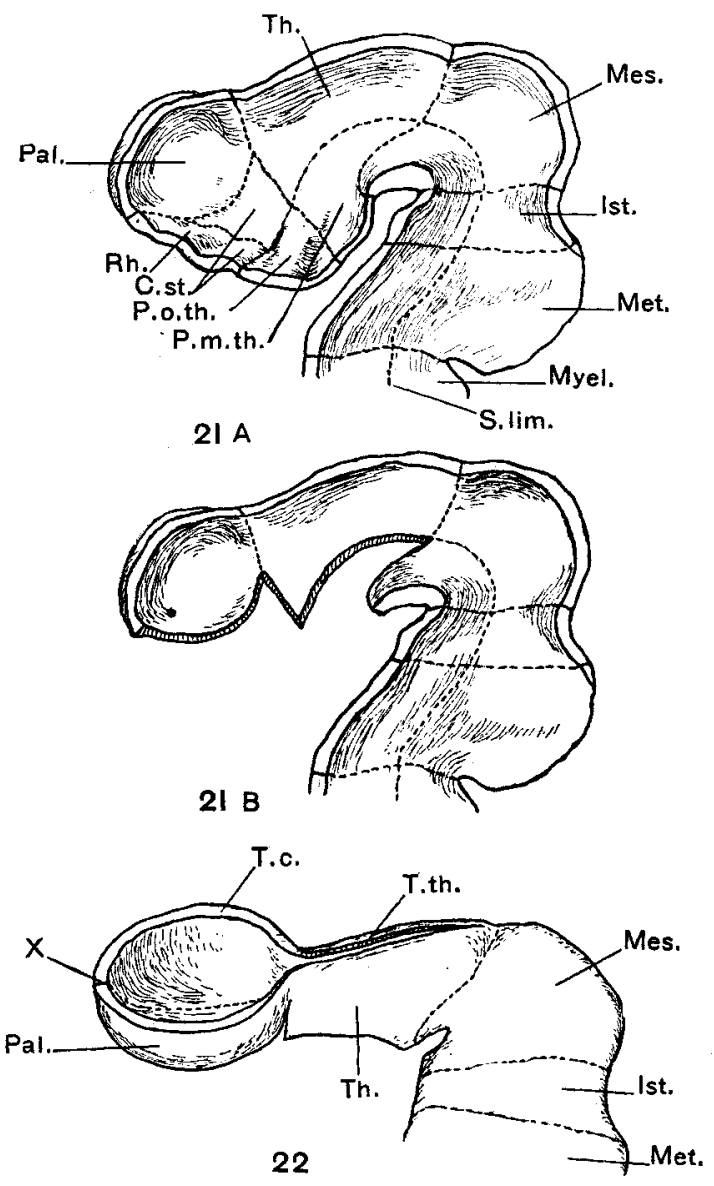

Fig. 21 A Medial sagittal section of a His' model of the brain at the end of the fourth week (modified from Spalteholz). C.st., corpus striatum; Ist., isthmus; Mes., mesencephalon; Met., metencephalon; Myel., myelencephalon; Pal., pallium; P.m.th., pars mamillaris hypothalami: P.o.th., pars optica hypothalami; $R h$., rhinencephalon; S.Lim., sulcus limitans; Th., thalamus.

Fig. $21 \mathrm{~B}$ Right half of a His' model of the brain at end of fourth week, from which the anlagen of the rhinencephalon, corpus striatum, pars optica and pars mamillaris hypothalami have been removed. The cut edges are lined.

Fig. 22 Model resulting from the approximation of the cut surfaces as indicated in the text. T.c., taenia corebri; T.th., ta enia thalami; $X$, marks the line of union between the original ventro-mesial edges of pallial anlagen. Other letters as in figure $21 \mathrm{~A}$. 
find the hippocampal formation developed in the edges of the pallial cup posteriorly, and above the fimbria we find choroidal invaginations of the ependyma.

Turning to the thalamus, it will be seen that the absence of the pars optica and pars mammillaris hypothalami would materially reduce both the volume of the thalamus and the size of its ventricular cavity.

The use of such a model is justified only in so far as it helps to demonstrate the mechanical tendencies that would arise in a brain in which these areas are missing from the start. The brain at this stage of development was taken because, while the relations are simple, it is yet possible to outline the areas occupied by the corpus striatum, and so forth, fairly accurately.

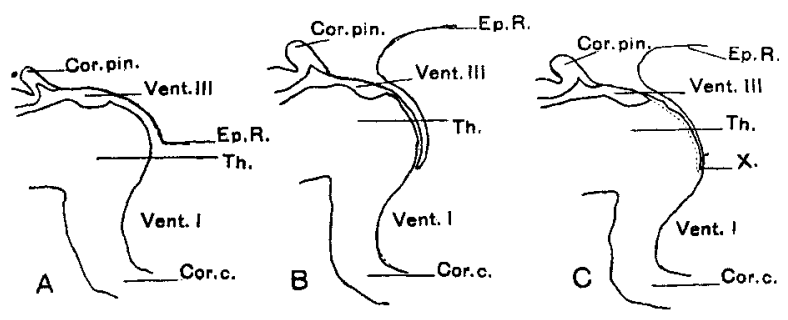

Fig. $23 \mathrm{~A} \mathrm{~B}$ and C. Diagrams of medial sagittal sections through the brain illustrating the hypothetical closure of the connection between the cavity of the cerebral vesicle and the third ventricle. Cor.c., cortex cerebri; Cor.pin., pineal body; Ep.R., ependymal roof; Th., thalamus; Vent.I., cavity of cerebral vesicle; Vent.III., third ventricle; $X$, in figure $23 \mathrm{C}$. indicates the final point of attachment of the much expanded thin roof to the front of the thalamus.

Sometime during the development of this case the condition of hydrocephalus set in and, as a result, the roof of the cerebral vesicle bulged upward. If one refer now to the diagrams (fig. 23 ), it can be readily seen how the discontinuity in the cavity of the already reduced third ventricle might be brought about through pressure of the expanding roof of the cerebral vesicle. This thin cerebral roof being confined above by the skull, extended backward as a pocket over the thalamus. Pressure of the fluid contents being transmitted equally in all directions would then tend to close the fore part of the third ventricle. This closure might subsequently be followed by adhesion be- 
tween the approximated walls and finally by complete obliteration of the ependyma. Such an explanation is however purely heoretical, as there is no way of determining the time relation etween the onset of hydrocephalus and the occlusion of the interior portion of the third ventricle.

\section{REVIEW OF CASE REPORTED BY O. NAEGELI}

In the case reported by Naegeli (17) the cerebrum was represented by an unpaired, thick walled vesicle, having a very slight attachment to the massive thalamus.

The basal ganglia were quite defective and could not be definitely identified. He described, however, a thin plate of embryonic cells in the region of junction between the thalamus and cerebrum which he concludes may represent these structures.

No olfactory bulb or stalk was present but he describes the hippocampal formation as being well developed, and the fimbria as containing medullated fibers. In figure 29 of his report he shows the cornu ammonis in transverse section and it is strikingly similar to sections through this region in the present case. Unfortunately, he has not described the relations of the hippocampus except to mention that it is a distinctly paired formation, so further comparison is impossible. The fornix is also mentioned as an unpaired bundle which divides into symmetrical halves to end in the region of the corpora mammillaria. The relations of this fornix to the fimbriae are not clear.

The cortex of the cerebral vesicle showed a distinctly laminated arrangement of its cells and was quite markedly thicker than normal-the greatest increase in thickness being in the deep or polymorphic stratum. In figure 42 of his report he shows a carmine stained section through the cerebral cortex, in which the cell lamination is almost precisely the same as that described as appearing under low magnifications in the present case. $\mathrm{He}$ also found a few poorly medullated radial fibers in the layer of large pyramidal cells. No tangential fibers were present.

The thalamus was massive and of nearly normal form, but the two halves were strongly fused in the mid-line ventrally. 
He does not describe any connection between the remains of the third ventricle and the cavity of the cerebral vesicle. From his figures I am led to believe that this connection was interrupted. The attachment of the thalamus to the cerebrum was very slight and wholly basal. Into this region, projection fibers converge from the lateral nuclei of the thalamus, constituting an atypical thalamic radiation. Ventrally the fibers of the two sides decussate and end blindly in the basal region of the cerebrum, which before has been alluded to as the probable representative of the corpus striatum.

It is thus seen that, as in the present case, the third ventricle has been considerably reduced in volume and its connection with the cavity of the cerebral vesicle has also apparently been entirely interrupted.

A single median optic nerve was present which divided posteriorly at a partial decussation into paired optic tracts. Infundibulum, corpora mammillaria and lateral geniculate bodies could be distinguished and a commissure of Meynert is described crossing in the tuber cinereum. Dorsally the habenular bodies were prominent, together with the posterior commissure and fasciculus retroflexus of Meynert. Medullated fibers were found in the taenia thalami (stria medullaris thalami).

The thalamic nuclei were not definitely marked out, but the whole thalamic mass was relatively rich in well formed ganglion cells together with more numerous embryonic elements and neuroblasts, being thus similar in these respects to the present case.

From the region of the interpeduncular ganglion caudad, the brain stem was much distorted by a malformation quite independent of the cyclopian condition. A split had occurred in the mid-line, resulting in a more or less complete separation of the brain stem and cerebellum into right and left halves. Relations were further complicated by the presence of an additional flexure in the brain stem and by the bending dorsally of a considerable portion of the split cord so that it came to lie upon the malformed brain stem halves within the skull cavity. A considerable amount of fusion between the cord and underlying brain stem halves was also present. 
Notwithstanding these malformations, the cranial nerves from the oculomotor caudad and most of the fiber systems with their nuclei could be identified in the brain stem. There was a complete absence, however, of the pyramidal system throughout.

Naegeli calls attention to von Monakow's (16) classification of fiber systems and nuclei into phylogenetically old and phylogenetically young groups, and points out that only the former are to be identified throughout in his case.

He concludes from the striking resemblance between the arrangement of structures in the forebrain region in his case and those obtaining in the forebrain of teleosts, and also from the complete absence of so-called phylogenetically young fiber systems, that the condition of the brain in cyclopia may represent an arrest of development at a phylogenetically early stage.

It is evident from the above that the prosencephalic disturbance here noted, dependent upon the cyclopian condition, was not so extensive as in the present case.

\section{CONCLUSION}

In the case I have reported, there is a very marked superficial resemblance between the forebrain vesicle and the telencephalon in teleosts. The resemblance, however, is only superficial, for the thickened basal structures present in this case are altogether pallial. In teleosts the basal nuclei form the bulk of the thickened base of the telencephalon, while in this case these basal structures are absent.

The absence of the so-called phylogenetically young fiber systems is sufficiently explained by the lack of complete development of the suprasegmental neurones whose processes make up the bulk of such systems normally. There can be no doubt that the very slight attachment of the thalamic mass to the cerebral vesicle had much to do with the growth inhibition of the cortical neurones.

The presence of a well marked hippocampal formation while the rhinencephalon, as before defined, is entirely wanting, may be explained on mechanical grounds. Such a finding offers the 
strongest evidence that the condition of the brain in cyclopia cannot represent an arrest of development at a phylogenetically early stage.

The observations in connection with the histological structure of the cortex, which will be more fully recorded elsewhere, have, I think, shown the value of a close investigation into the finer anatomy of the abnormal nervous system. It is in such cases as this that the key to many of the problems concerning the development of the normal brain may be found.

My conclusions can best be summarized as follows:

1. That the central nervous system in this case of cyclopia does not show any evidence that may be taken to indicate an arrest of its development at an early phylogenetic stage. From a study of Naegeli's paper, and from what I have seen in other cyclopian brains in my possession, I am led to the conclusion that any apparent indication of such a reversion is purely superficial in character and may be explained on mechanical grounds.

2 . That the persistence of so-called phylogenetically old neurone systems in the brain, and the absence of phylogenetically young systems, is due solely to the absence during development of certain portions of the forebrain in the ventral region (midline), and to the interference with the mechanics of growth caused thereby.

3. That the condition of development of the primary forebrain will present a new mechanical problem in each case of cyclopia, depending upon the extent of the primary absence of tissue anlagen, and that the extent of this 'lesion' cannot always be judged by the condition of the cyclopian eye. In contrast to this, the condition of development in the brain stem in each case, provided no other malformations are present, will be very similar; and such abnormalities as are present will be due to the absence of fiber systems of the suprasegmental type.

4. That the condition of cortical development is such as to confirm the opinion already expressed by Bolton and Moyes (3), namely: that the sensory or afferent fibers to the cortex develop in all probability before the motor or efferent fibers from the cortex. 
5. That the initial stimulus resulting in the differentiation of specialized efferent cortical neurones is probably dependent upon the arrival of these afferent fibers in the cortex.

6. That the condition of development in the cerebrum of this case offers further proof that the differentiation of the cortex into histologically distinct areas precedes the development of the convolutional pattern.

\section{LITERATURE CITED 1}

(1) Blackburn, I. W. 1907 Anomalies of the encephalic arteries among the insane. Jour. Comp. Neur., vol. 17., no. 6.

(2) Bolton, J. S. 1910 A contribution to the localization of cerebral function based on clinico-pathological study of mental disease. Brain, vol. 33 .

(3) Bolton, J. S. and Mores, J. M. 1912 The cytoarchitecture of the cerebral cortex of a human foetus of eighteen weeks. Brain, vol. 35 .

(4) Bonne, Ch. 1906 L'écorce cérébrale. Revue Générale d'Histologie, Renaut et Regaud, no. 2.

(5) CAJAL, S. Ramón 1909 Histologie du système nerveux de l'homme et des vertébrés. Trad. par Azoulay, tome 1.

(6) 1911 Idem, tome 2.

(7) Campetel, Alfred W. 1905 Histological studies on the localization of cerebral function. Cambridge.

(8) DaReste, C. 1891 Recherches sur la production artificielle des monstres. II Ed. Paris.

(9) Gravelotte, E. 1905 Contribution à l'étude des anomalies de développement de l'extremité céphalique-un cas de cyclopie. Thèse.

(10) Harrison, R. G. 1906 Further experiments on the development of peripheral nerves. Am. Jour. Anat., vol. 5.

1 No attempt has been made here to prepare a complete bibliography of the literature dealing with cyclopia, for the great majority of the cases reported have no bearing upon the subject of this paper. A complete critical review of the literature up to 1872 has been made by Kundrat (12). For a short review of the subject of cyclopia up to 1897 and a statement of the various theories that have been held regarding the nature and cause of this malformation, reference may be made to Naegeli's paper (17). A somewhat more extensive historical survey of the subject, with a bibliography may be found in the thesis by Gravelotte (9). Most of the important contributions of recent date on this subject have been made by the application of experimental methods in the production of this malformation in lower forms. Some of the more important papers in this connection are cited, as well as some of the literature bearing upon the general subject of teratology. Papers dealing with the histological arrangement of the elements in the normal cortex, which have been consulted in connection with the study of the cortex in this case, are also referred to in this list. 
(11) JACKSON, HARRY 1909 Cyclopian monsters: Some general observations with report of a case. Jour. Am. Med. Assoc., vol. 53, no. 18.

(12) V. KUndrat 1882 Arhinencephalie als typische Art von Missbildung. Graz.

(13) Lewis, WARRen H. 1909 Experimental production of cyclopia in the fish embryo (Fundulus heteroclitus). Anat. Rec., vol. 3, no. 4.

(14) MaLL, F. P. 1905 On the development of the blood-vessels of the brain in the human embryo. Am. Jour. Anat., vol. 4.

(15) 1908 A study of the causes underlying the origin of human monsters. Philadelphia.

(16) von Monakow, C. 1895 Experimentelle und pathologische-anatomische untersuchungen über die Haubenregion, den Sehhügel und die Regio subthalamica, nebst Beiträgen zur Kenntniss früh erworbener Grossund Kleinhirndefecte. Arch. f. Psychiat., Bd. 27.

(17) NAEGELI, O. 1897 Ueber eine neue mit Cyclopie verknüpfte Missbildung des Centralnervensystems. Archiv f. Entw. Mech., Bd. 5, H. 1.

(18) Opfenheim, H. 1911 Text-book of nervous diseases. Vol. 2. Trans. by Alex. Bruce. Edinburgh.

(19) Roux, W. 1895 Gesammelte Abhandlungen über Entwickelungsmechanik. Bd. 1, pp. 348, 804. Bd. 2, pp. 281. 909.

(20) Sabin, Florence R. 1901 An atlas of the medulla and midbrain. Baltimore.

(21) 1911 Description of a model showing the tracts of fibers medullated in a new-born baby's brain. Am. Jour. Anat., vol. 11, no. 2.

(22) Schwalbe, E. 1906 Die Morphologie der Missbildungen des Mensehen und der Tiere. Teil 1.

(23) SмIтн, G. Ellior. 1907 A new topographical survey of the human cerebral cortex. Jour. Anat. and Phys., vol. 41.

(24) STOCKARD, C.R. 1907 The artificial production of a single median cyclopian eye in the fish embryo by means of sea water solutions of magnesium chloride. Arch..f. Entw. Mech., Bd. 23.

(25) 1908 The question of cyclopia: one-eyed monsters. Science, vol. 28.

(26) 1909 The development of artificially produced cyclopian fish, 'The magnesium embryo.' Jour. Exp. Zool., vol. 6.

(27) 1910 The influence of alcohol and other anaesthetics on embryonic development. Am. Jour. Anat., vol. 10. no. 3.

(28) Wrider, H. H. 1908 The morphology of cosmobia. Am. Jour. Anat., vol. 8. 


\section{ABBREVIATIONS}

\section{FIGURES 24 TO 47}

Figures 24 to 47 are drawn from a series of transverse sections through the cyclopian brain stem, stained by a modified Weigert method followed by Upson's carmine. The drawings which are here reproduced at a magnification of $\times 2.5$, are all so arranged that the right and left sides of the sections correspond to the right and left sides of the page respectively. In examining this series it is well to bear in mind that in this brain stem two marked flexures persist. Thus for example, in figure 34, the midbrain and medulla appear in almost transverse section while the intervening pons is cut horizontally for the most part. An explanation of the abbreviations used in these figures will be found in the accompanying list.

Aq.c., aquaeductus cerebri

$B$, thalamic fibers that have wandered ventrad into the pia

$B r . c .$, brachium conjunctivum

C.c., canalis centralis

C.hb., commissura habenularum

C.isl., cell islands in second layer of cortex cerebri

$C . i .$, colliculus inferior

$C . L$., continuation into the medulla of the lateral column of the cord

Cor.cer., cortex cerebri

Cor.pin., corpus pineale

C.p., commissura posterior cerebri

C.s., colliculus superior

C.t., corpus trapezoideum

D.Br.c., decussatio brachii conjunctivi

Dec.l., decussatio lemniscorum

$D . N . V$, decussating tract of $\mathrm{N}$. trigeminus

D.t.d.M., decussatio tegmenti dorsalis Meynerti

F.a.e., fibrae arcuatae externae

$F . a . i$, fibrae arcuatae internae

$F . c .$, funiculus cuneatus

F.l.m., fasciculus longitudinalis medialis

F.r.M., fasciculus retroflexus Meynerti

L.l., lemniscus lateralis

L.m., lemniscus medialis

L.s., lemniscus superior

N.C.I., first cervical nerve

N.III., $\quad$ N. oculomotirii

N.IV., $\quad$ N. trochlearis
$N . V$
$\mathrm{N}$. trigemini
N.V.m.
$\mathrm{N}$. trigemini (motor)
$N . V I$,
N. abducentis
N.VII.,
N. facialis
N.VIII., coch.N. cochleae
$N . V I I I .$, vest., N. vestibuli
$N . I X, X ., \quad \mathrm{N}$. glossopharyngei et vagi
N.X.,
vagi
$N . X I$,
N. glossopharyngei et
N.XII.,
N. accessorii

$N u . a .$, nucleus arcuatus

$N u . a . c .$, nucleus alae cinerae

$N u . a m b .$, nucleus ambiguus

Nu.c.a., nucleus of the anterior horn

$N u . c . i .$, nucleus colliculi inferioris

$N u . \operatorname{coch}$., nucleus $\mathrm{N}$. cochleae ventralis

$N u . \operatorname{coch} . d$., nucleus $\mathrm{N}$. cochleae dorsalis

Nu.c.r., nucleus of restiform body

$N u . d .$, nucleus dentatus

Nu.emb., nucleus emboliformis

Nu.f.c., nucleus funiculi cuneati

Nu.f.g., nucleus funiculi gracilis

Nu.f.l.m., nucleus faciculi longitudinalis medialis (Darkschewitsch)

$N u . g .$, nucleus globosus

$N u . h . b .$, nucleus habenulae

$N$ u.l.l., nucleus lemnisci lateralis

Nu.lat.1,2,3, nuclei distinguished in the lateral portions of the thalamic mass

Nu.lat.th., lateral thalamic nucleus

Nu.med.th., medial thalamic nucleus 
Nu.m.N.V., nucleus motorius N. trigemini

Nu.N.coch., nucleus N. cochleae ventralis

Nu.N.coch.d., nucleus $\mathrm{N}$ cochleae dorsalis

Nu.N.vest., nucleus $\mathrm{N}$. vestibuli lateralis

Nu.N.III., nucleus N. oculomotorii

$N u . N . I V .$, nucleus $\mathrm{N}$. trochlearis

$N u . N . V I .$, nucleus $\mathrm{N}$. abducentis

$N u . N . V I I$. , nucleus N. facialis

$N u . N . X I I$, nucleus N. hypoglossi

Nu.XII., nucleus N. hypoglossi

Nu.o.a.d., nucleus olivaris accessorius dorsalis

Nu.o.a.m., nucleus olivaris aucessorius medialis

Nu.o.i., nucleus olivaris inferior

Nu.o.s., nucleus olivaris superior

Nu.Pon., nuclei pontis

$N u . r$. nucleus ruber

$P$., thickened layer of pia enclosing midbrain and extraventricular portion of thalamus
Pl.ch.III., choroid plexus of third ventricle

Rad.th., thalamic radiations. (Ventral fibrillar area)

R.d.N.vest., radix descendens $\mathrm{N}$. vistibuli

R.d.N.V., radix descendens (mesence$\mathrm{p}$ alica) $\mathrm{N}$. trigemini

S.s., striae acusticae

S.a.p., stratum album profundum

S.g., substantia gelatinosa Rolandi

S.i.l., stratum interolivare lemnisci

$S t . z .$, stratum superficiale of cortex cerebri

$T . s .$, tractus solitarius

T.th.I., attachment of the ependymal roof or cerebral vesicle over the anterior aspect of thalamus

T.th.III., taenia thalami

$T . v . q .$, taenia ventriculi quarti

T.s.N.V., tractus spinalis N. trigemini

$V$ ent.I., cavity of cerebral vesicle

Vent.III., ventriculus tertius

$V . q .$, ventriculus quartus

$X$., ependymal diverticulum from aquaductus cerebri 


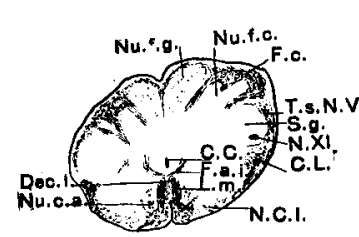

24
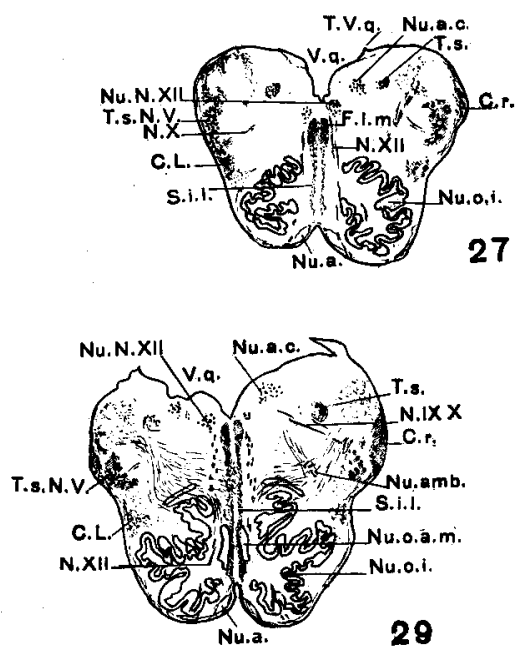

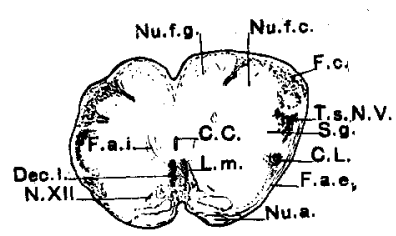

26.
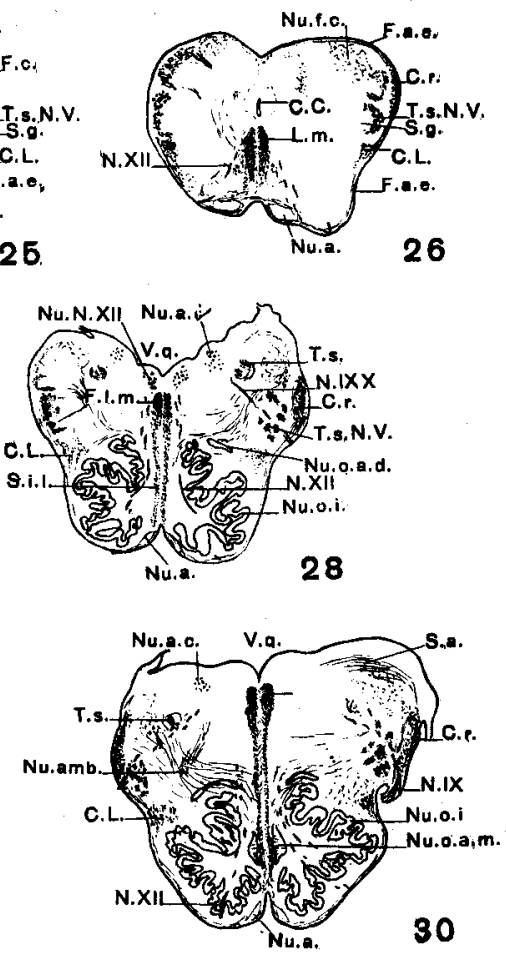

दर्द?

$525 \%$

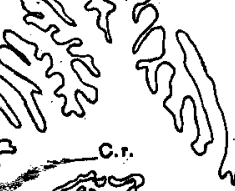

$2 \mathrm{~m}=$

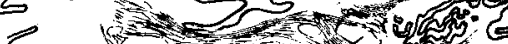

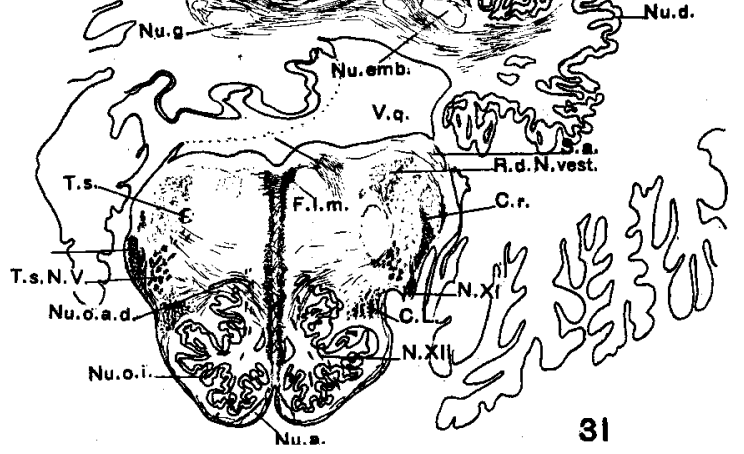




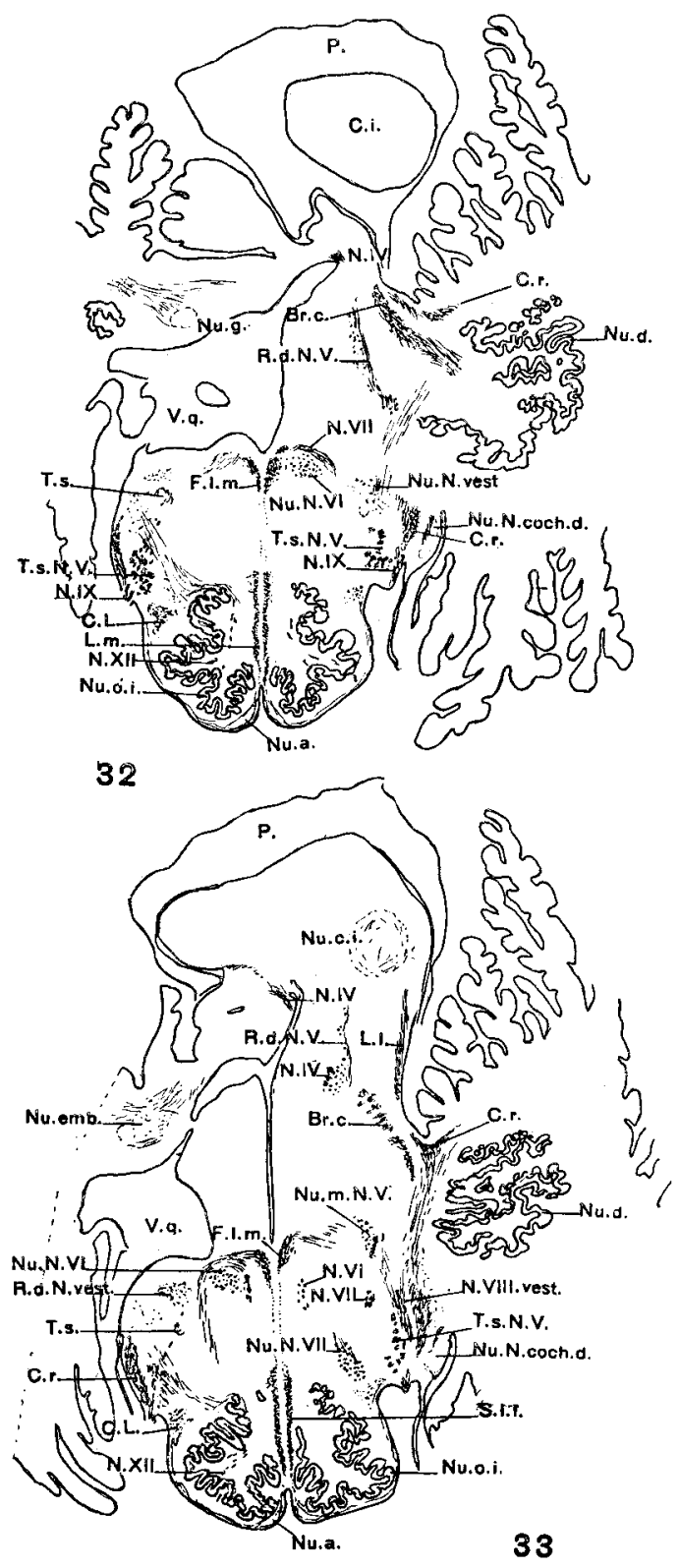




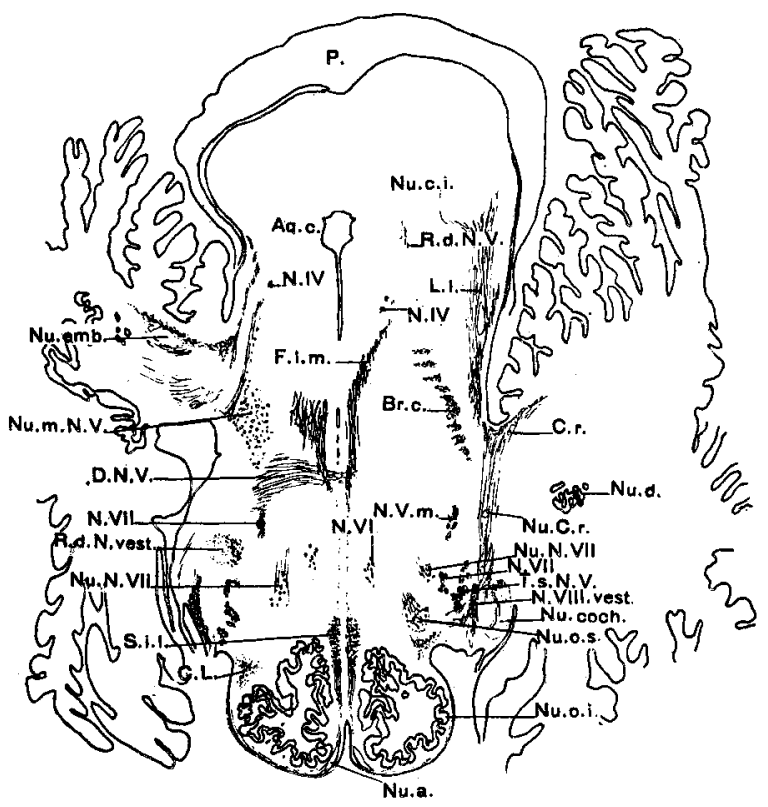

34

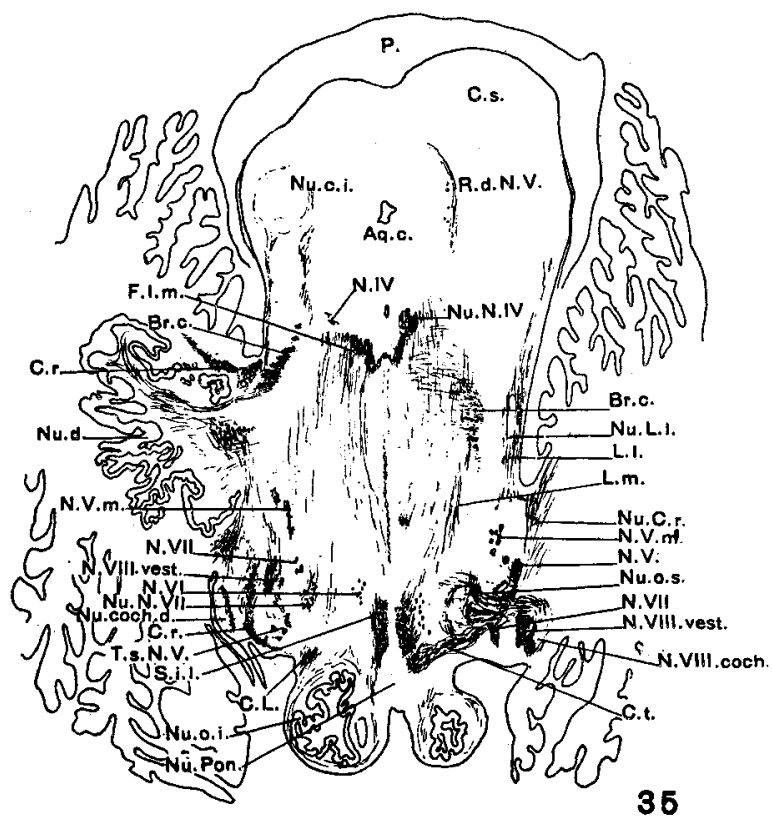



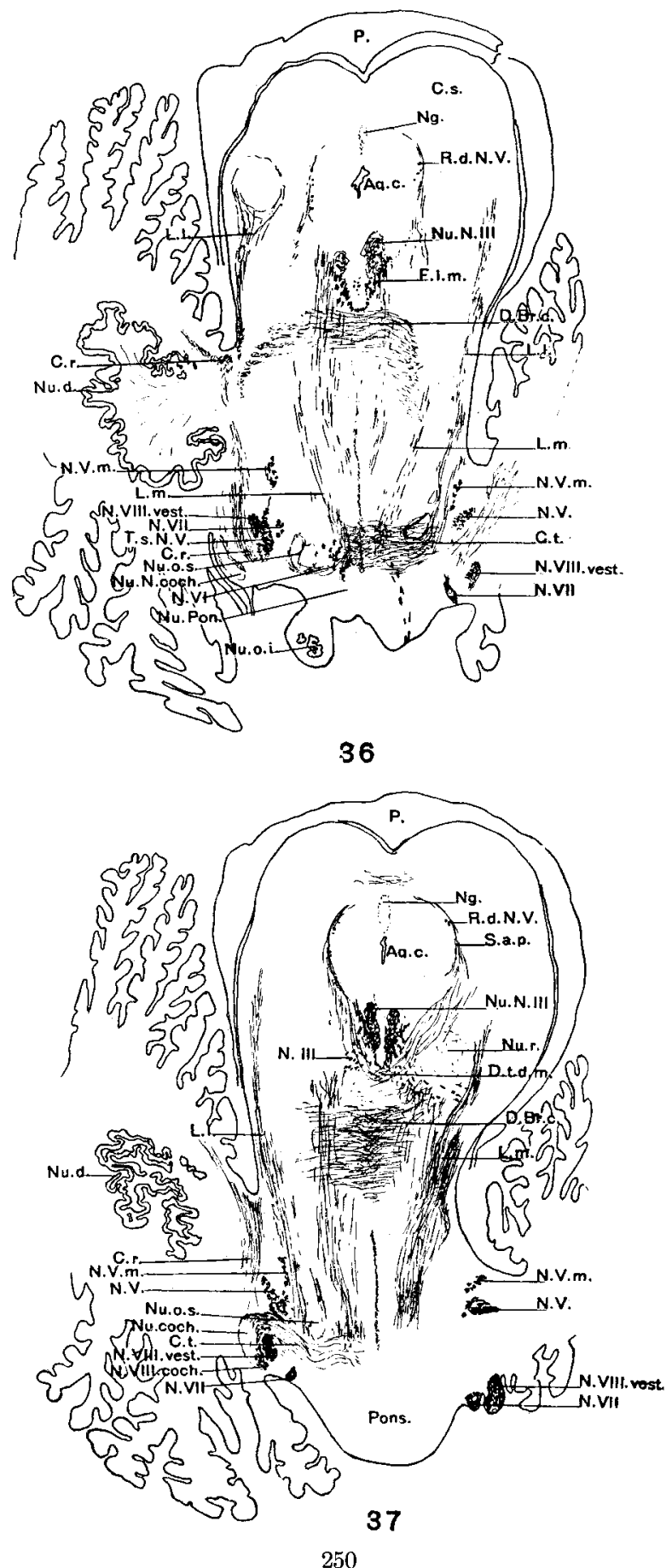

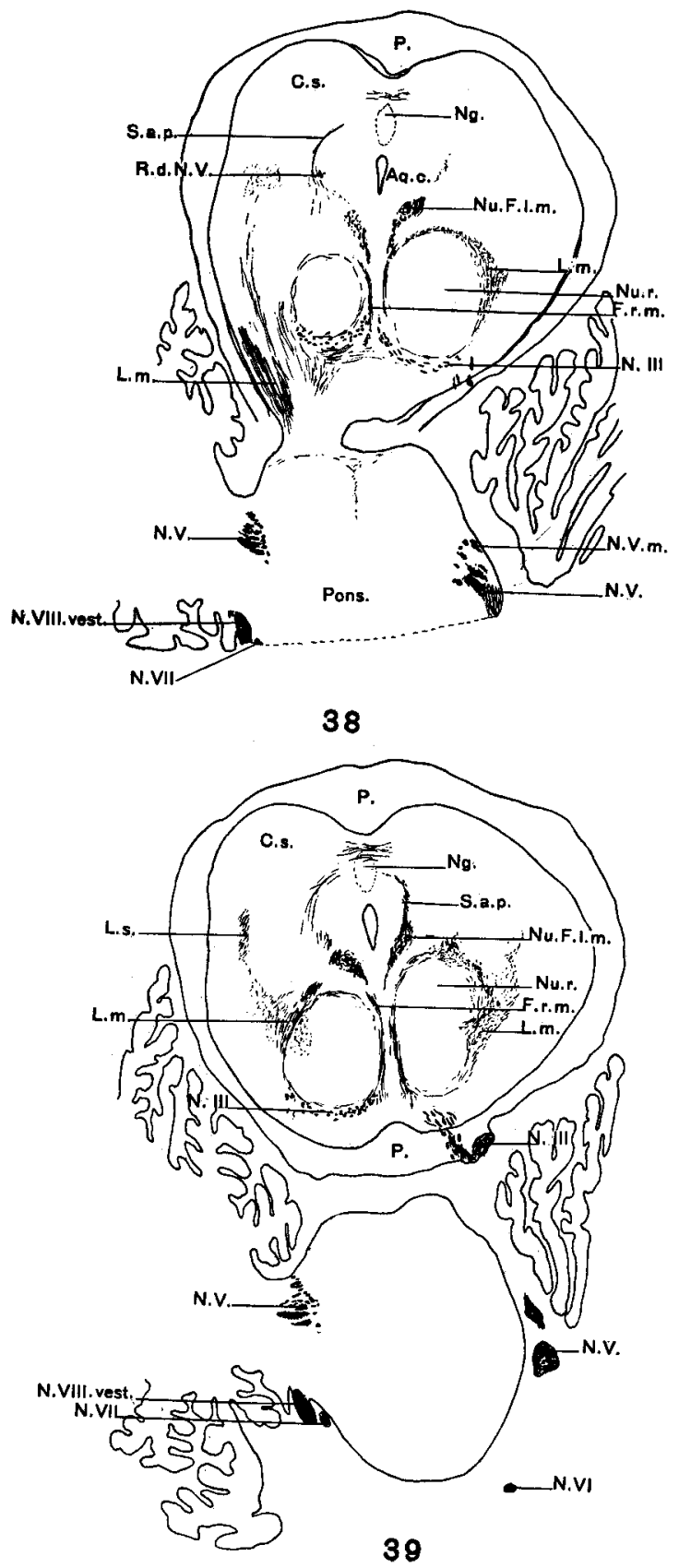

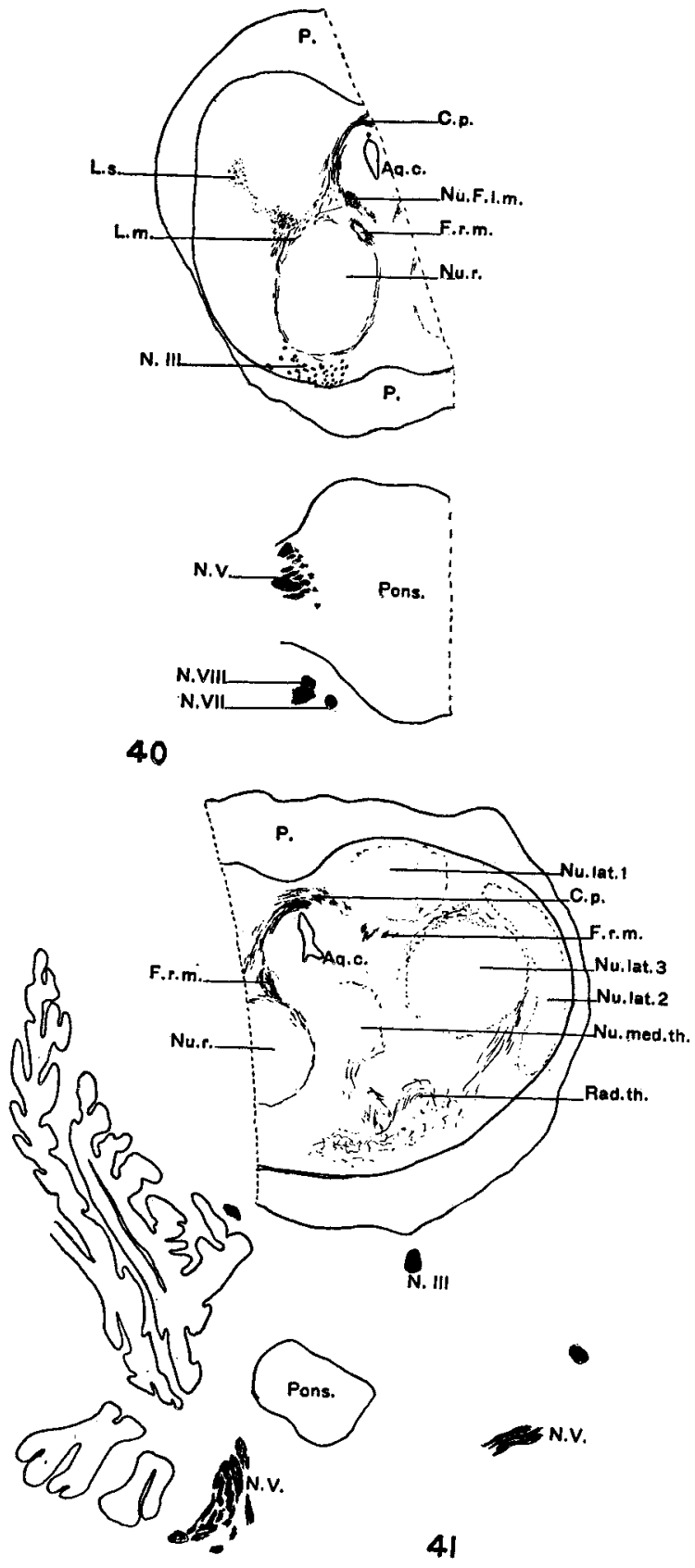


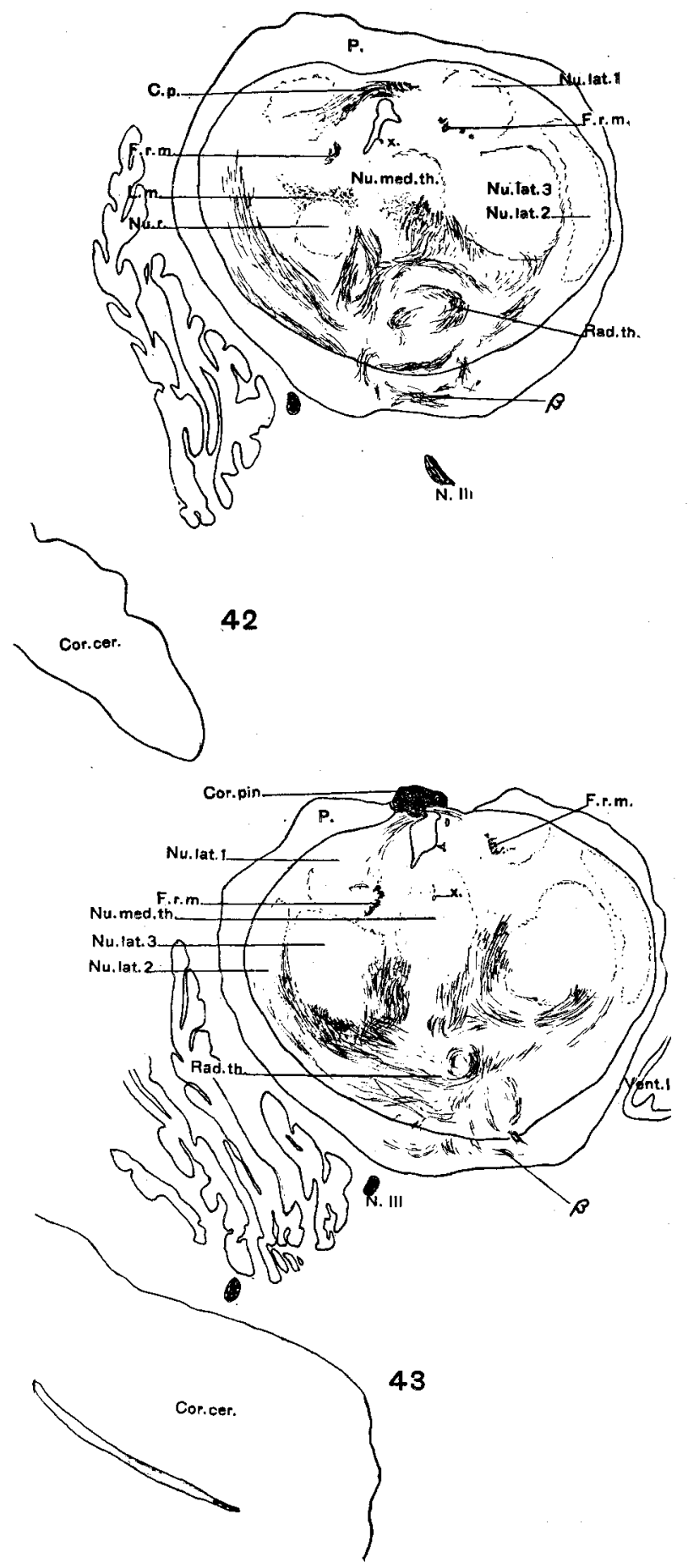




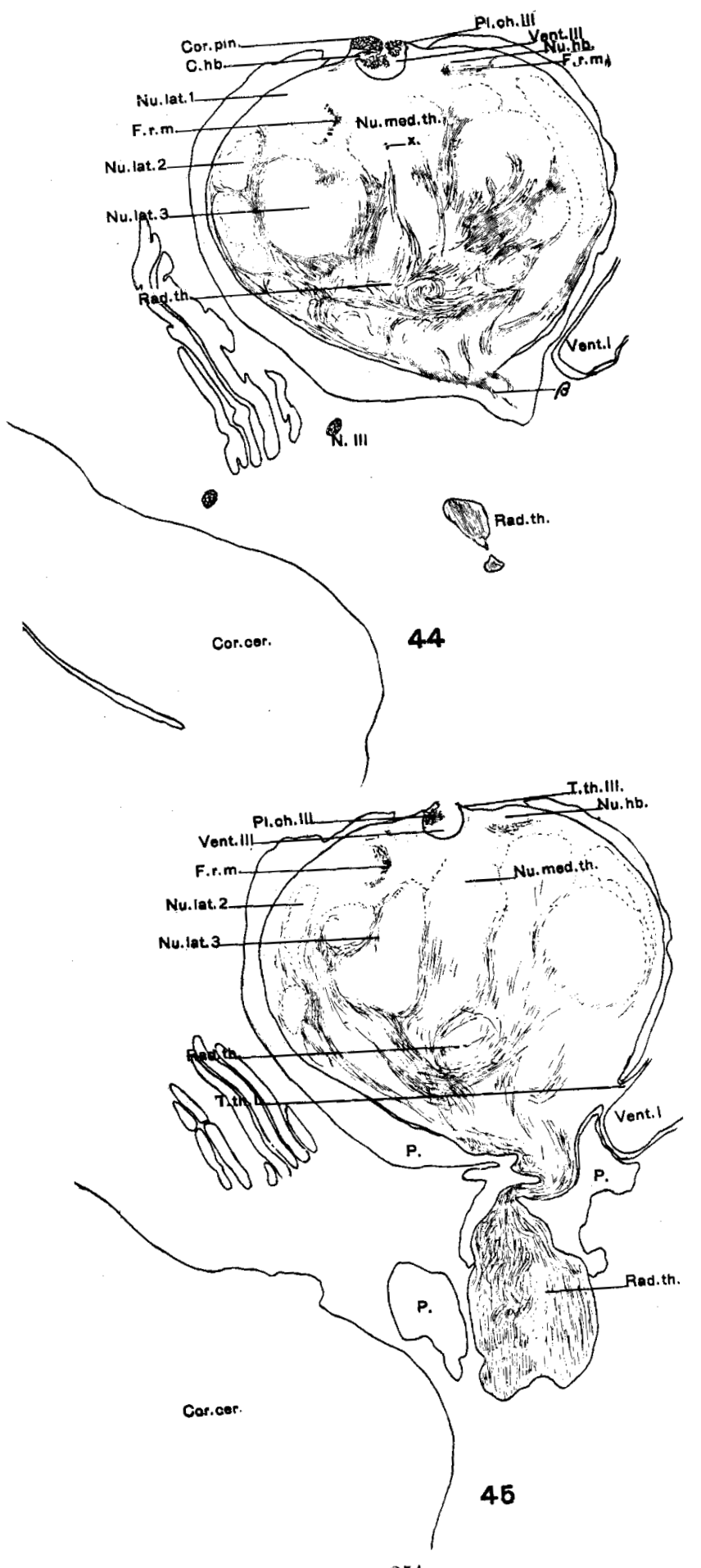



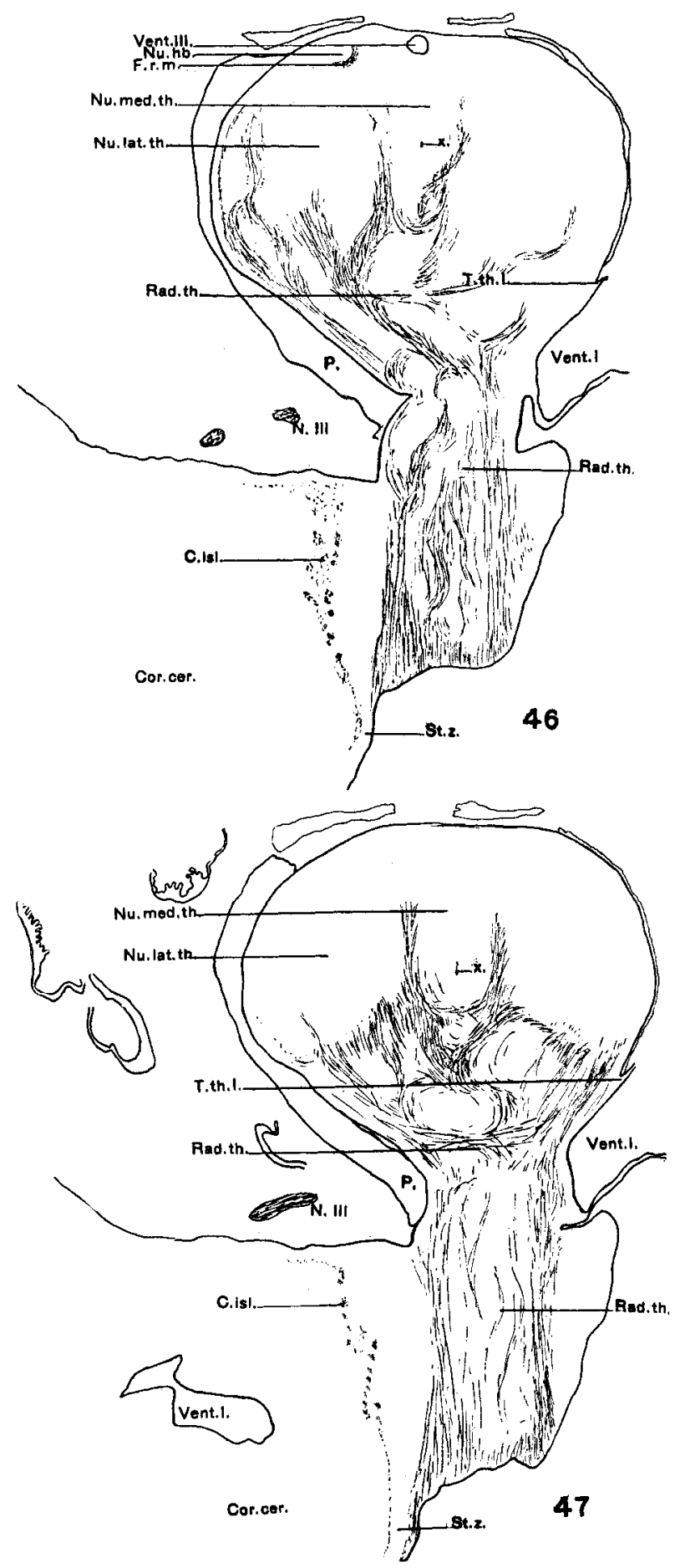

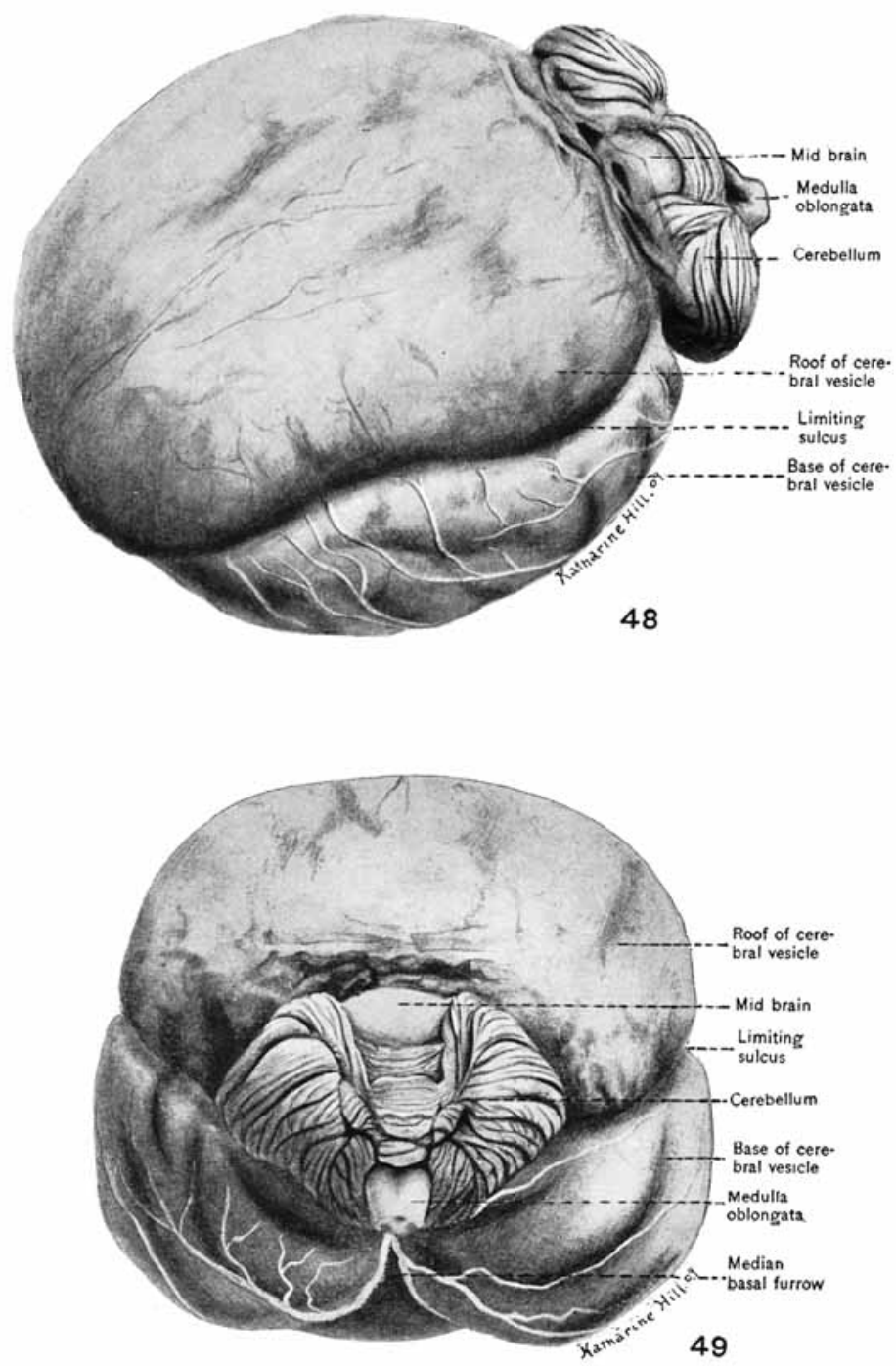

EXPLANATION OF FIGURES

48 Dorso-lateral view of entire brain. $\times \frac{2}{3}$.

49 Posterior view of brain. $\times \frac{2}{3}$. 

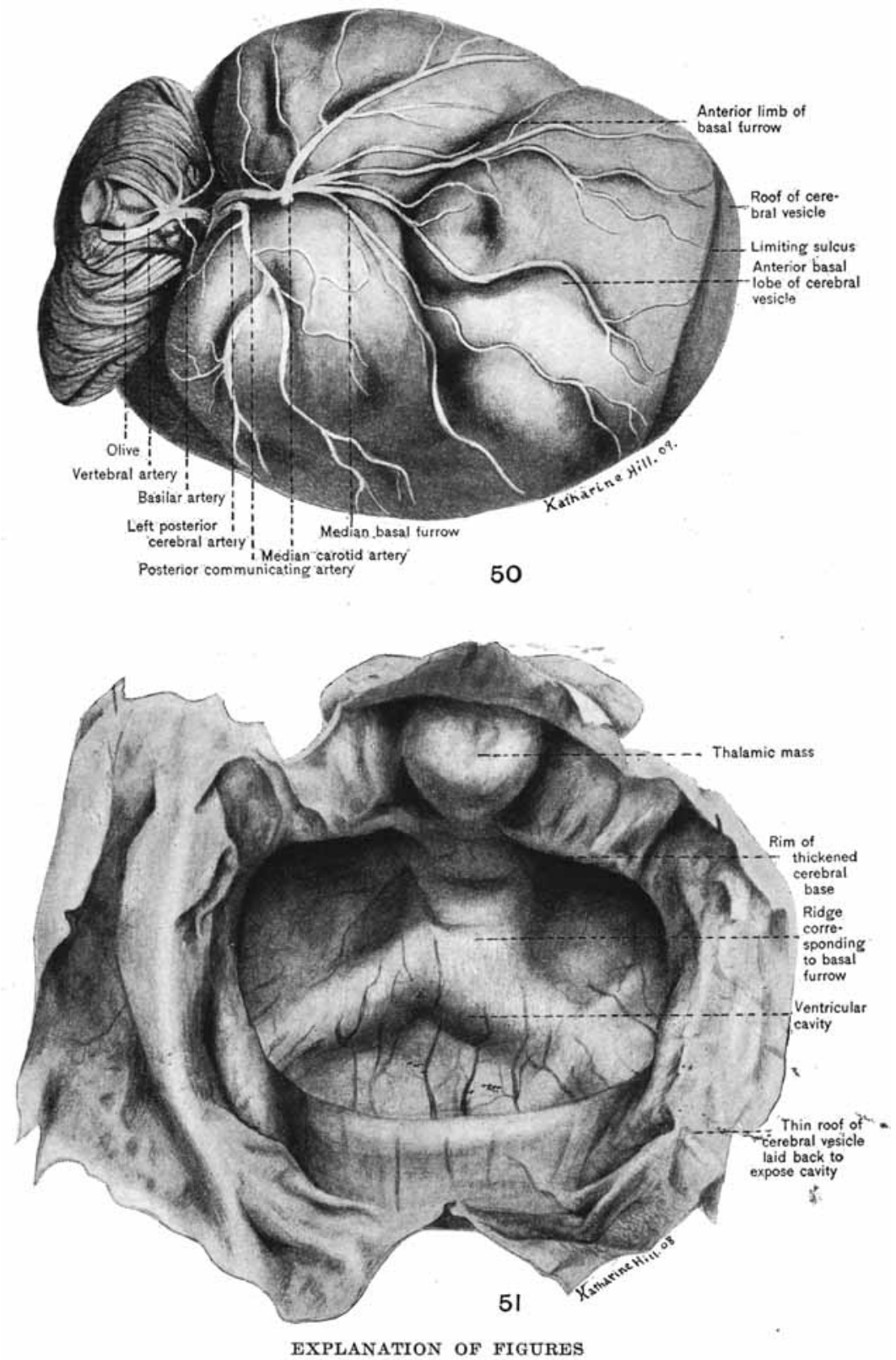

50 Ventral view of brain. $\times \frac{2}{3}$.

51 Dorsal view of brain in front, with the thin roof of the forebrain vesicle opened up. $\times \frac{2}{3}$. 